\title{
Cinefluorographical study of the burrowing movements in the common mole, Talpa europaea (Lipotyphla, Talpidae)
}

\author{
Petr P. Gambaryan, Jean-Pierre Gasc \& Sabine Renous
}

\begin{abstract}
The burrowing process of the common mole Talpa europaea Linnaeus, 1758 was investigated by the cinefluorography. During burrowing the humerus is abduced only on $25-30^{\circ}$. This abduction is realized by the rotation of the scapula around its longitudinal axis and by the translation of the clavicle in the sternoclavicular and claviculohumeral joints. The abduction of the shoulder joint is limited to $10-15^{\circ}$ by nearly complete coincidence of the articular surfaces of the scapular glenoid fossa and the humeral head. The shoulder joint extension diminishes the abductors momentum on 30-70\% and in this case they cannot develop the force determined in the experiments. M. flexor digitorum profundus is transformed in the ligament which origins on the median epicondyle of humerus and inserts on all the five ungual phalanges. This is an unique mechanism for the neutralization pronation momentum of the humerus abductors. The increasing of the pressure of the hands on the soil augments the tension of the $\mathrm{m}$. flexor digitorum profundus what hinders the pronation of the humerus. The increasing of the rotation of the antebrachium is necessary to maintain the hand in a parasagittal plane. An accretion of the humeral median epicondyle promotes decreasing of the humerus rotation. Humerus rotates during terrestrial locomotion in all tetrapods with sprawling limb position (humerus pronates in the propulsive phase and supinates in the swing phase). The recent Monotremata and probably primitive mammals use the humerus pronation for the lengthening of the stride. Mm. supraspinatus and infraspinatus prevent the humerus retraction. The widening of the humerus in these mammals is an adaptation to its rotation by the limited abduction and retraction. On the contrary, the widening of humerus in moles is an adaptation to its abduction by the limited rotation. Thus the convergent widening of the humerus in these animals is caused by the diametrically opposite functions.
\end{abstract}

KEY WORDS: Talpa europaea, cinefluorography, biomechanical analysis, burrowing.

Petr P. Gambaryan [gambar@PG5237.spb.edu], Zoological Institute, Russian Academy of Sciences, Universitetskaya nab.1, Saint Petersburg 199034, Russia; Jean-Pierre Gasc [Gasc@cimrs1.mnhn.fr], URA 1137 Laboratoire d'Anatomie comparée, Muséum national d'Histoire naturelle, 55 rue Buffon, 75231 Paris Cedex 05, France; Sabina Renous, URA 1137 Laboratoire d'Anatomie comparée, Muséum national d'Histoire naturelle, 55 rue Buffon, 75231 Paris Cedex 05, France.

\section{Киноренгеноскопическое исследования рытья обыкновенного крота, Talpa europaea (Lipotyphla, Talpidae)}

\author{
П.П. Гамбарян, Ж.-П. Гаск, С. Рено
}

РЕЗЮМЕ. С помощью киноренгеноскопии изучалось рытье обыкновенного крота Talpa europaea Linnaeus, 1758. При рытье плечо абдуцируется только на 25-30. Абдукция обеспечивается вращением лопатки вокруг ее длинной оси и перемещением ключицы в грудоключичном и ключичноплечевом суставах. В связи с почти полным совпадением суставных поверхностей гленоидной ямки лопатки и головки плеча, абдукция в плечевом суставе ограничивается $10-15^{\circ}$. Если вращение плеча будет увеличиваться, то абдукторный момент основных абдукторов будет уменьшаться. Из-за разгибания плечевого сустава может резко сокращаться абдукторный момент (на 30-70\%); в этом случае не сможет развиваться сила, которую мы экспериментально определили. M. flexor digitorum profundus превращен в сухожилие, которое начинается на медиальном надмыщелке плеча и оканчивается на всех пяти когтевых фалангах. Эта уникальная конструкция служит для нейтрализации пронаторного момента абдукторов плеча. Возрастание давления кистями на почву приводит к напряжению m. flexor digitorum profundus, который препятствует пронации плеча. Для поддержания кистей в парасагиттальной плоскости необходимо увеличение вращения предплечья. Разрастание медиального надмыщелка плеча способствует уменьшению вращения плеча. Во время наземной локомоции плечо вращается у всех тетрапод с расставленным положением конечностей (плечо пронирует в пропульсивной фазе и супинирует в переносной фазе). У современных однопроходных и, вероятно, у первичных млекопитающих пронация плеча служила для увеличения длины шага. $\mathrm{Mm}$. supraspinatus и infraspinatus препятствовали ретракции плеча. Расширение плеча у примитивных млекопитающих - адаптация к вращению плеча при отсутствии его ретракции и абдукции. Наоборот, у кротов расширение плеча связано с адаптацией к сокращению вращения при увеличении его абдукции. Конвергентное расширение плеча в этом случае возникает в связи с приспособлением к диаметрально противоположным функциям.

КЛЮЧЕВЫЕ СЛОВА: Talpa europaea, киноренгеноскопия, биомеханический анализ, рытье. 


\section{Introduction}

The process of burrowing includes the substrate loosening and throwing of the ground out of a tunnel, actions, which need a great amount of energy. Thus, adaptations to a subterranean mode of life, involving the excavation of long tunnels for feeding and other aspects of the life history, affect skeletal and muscular structures (Hildebrand, 1985). Among the most highly specialized diggers, the representatives of the family Talpidae, specifically Talpa europaea Linnaeus, 1758, exemplify a unique mode of burrowing where both components of the burrowing process are united into a single movement (Gambaryan, 1960), realizing the so called "lateral thrust method of digging" (Reed, 1951).

The definition of certain descriptive terms is necessary since the mole forelimb skeleton is peculiar in comparison to that of other mammals. The distal end of the mole humerus is directed forward and upward (Figs. 1-3) with respect to the shoulder joint whereas it is directed backward and downward in most other mammals. Theoretically such position of the humerus might be attained through hyperextension or hyperabduction. In Talpidae it is undoubtedly due to the hyperabduction since the medial epicondyle is situated laterally, whereas the lateral one is facing medially, and the caput humeri keeps its position on the dorsal surface of the bone. Therefore, the mole, "abduction", i.e. the moving of the distal end of the arm away from parasagittal plane, corresponds to the action of adductor muscles. The flexion of the shoulder joint is unusual also. Flexion of this joint in mole reduce the distance between cranial border of the scapula and humerus (unlike the flexion in other mammals, which reduce the distance between the caudal border of the scapula and humerus) and could be designated as hyperextension.

Consequently anatomical dorsal surface of the humerus is directed cranially, and the volar one caudally. The longitudinal axis of the humerus and its plane usually lie vertical (Figs. 2, 3). During lateral thrust a little
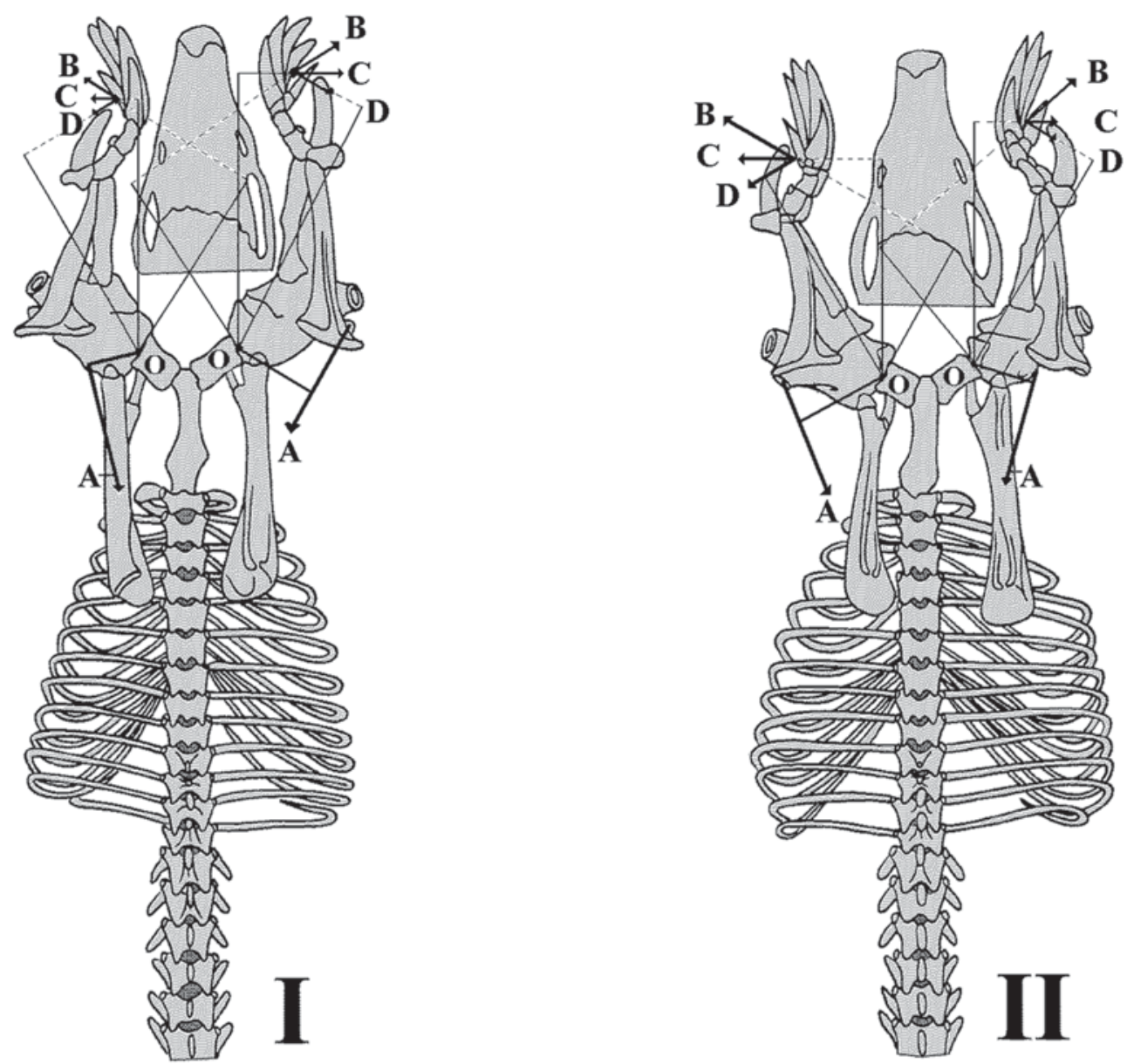

Figure 1. Mole, Talpa europaea, digging in dorsal view. Several successive positions (I to VI) of forelimbs during the removal of the soil drew from the cinefluorographic film taken at 60 frames per second.

The arrows A indicate sum vectors forces of the muscles taking place in movement in claviculohumeral joint $(\mathrm{O})$. Length of the vectors are proportional to physiological section of the muscles. $\mathrm{B}, \mathrm{C}$, and $\mathrm{D}$ are representing pressing force of the hand: $\mathrm{B}-120^{\circ}, \mathrm{C}-90^{\circ}, \mathrm{D}-60^{\circ}$ to the sagittal plane ( $\mathrm{C}$ is a usual direction pressing force of the hand; $\mathrm{B}$ and $\mathrm{D}$ are the extreme directions of the pressing force). Solid line - force moment; dotted line - direction of the force vectors. 

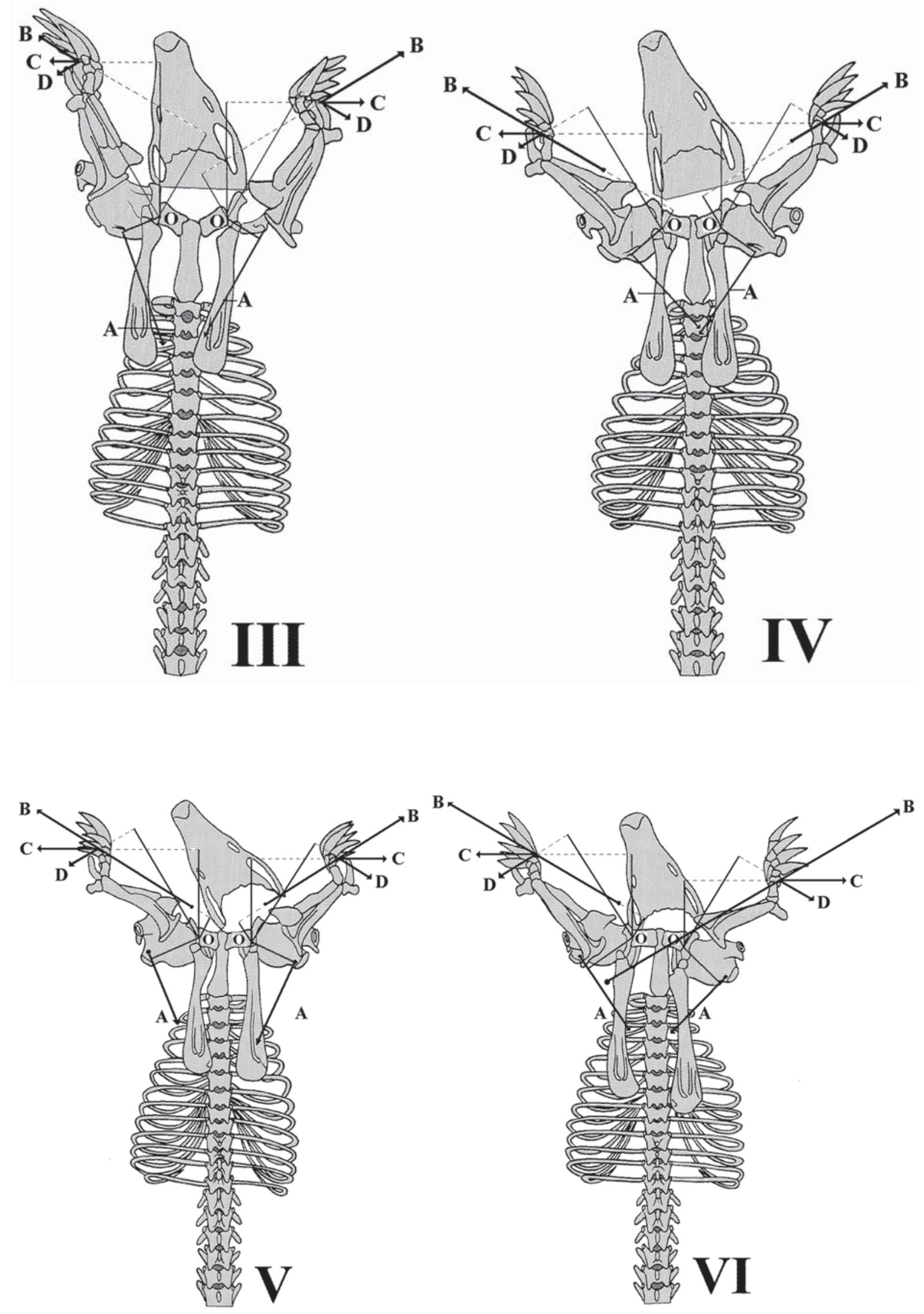


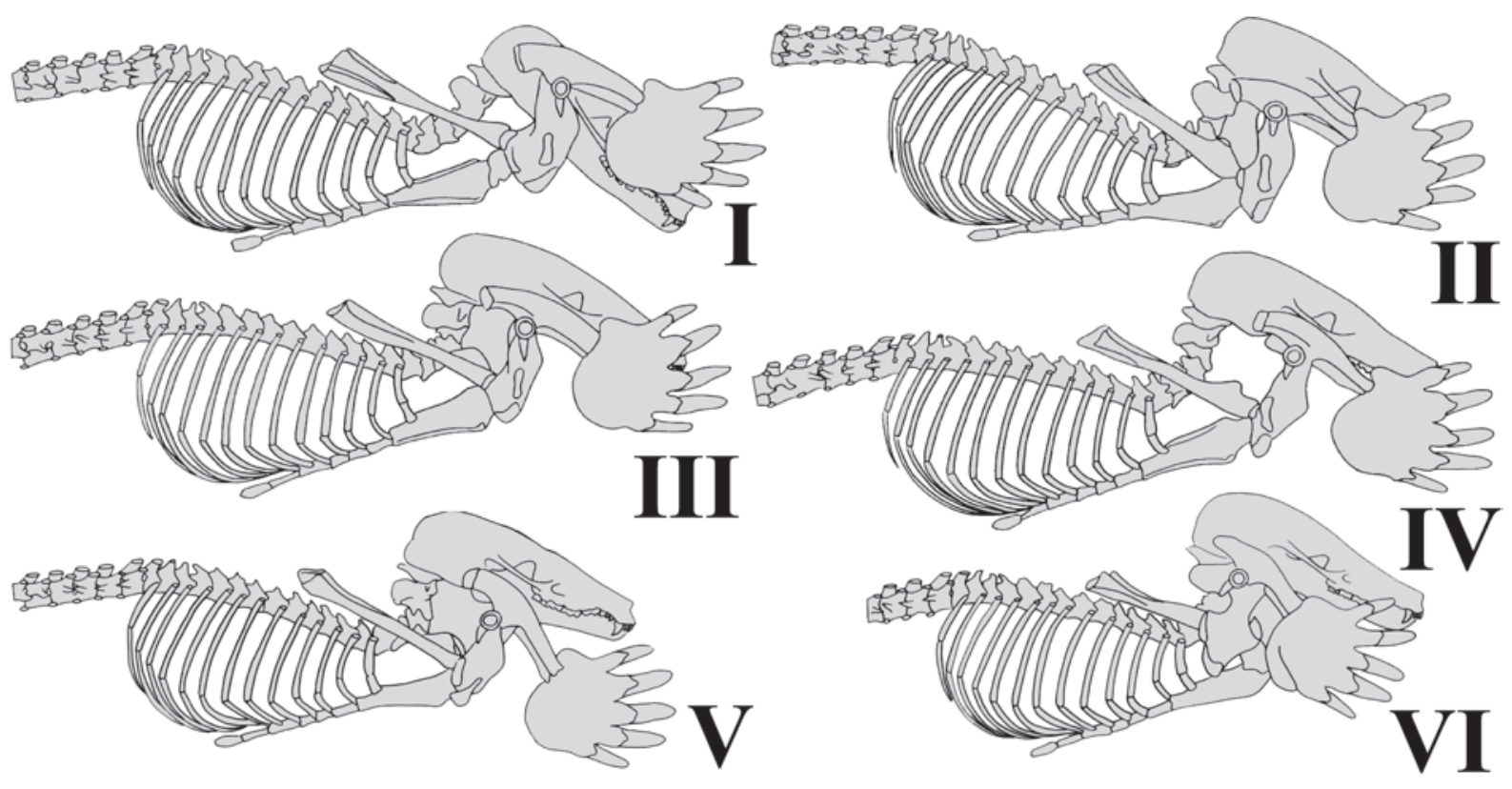

Figure 2. Lateral view of Talpa europaea skeleton syndesmological preparation in positions corresponding to those on the frames I-VI (Fig 1).

This view shows the flexio-extension in shoulder and elbow joints, not seen in dorsal view (Fig. 1).
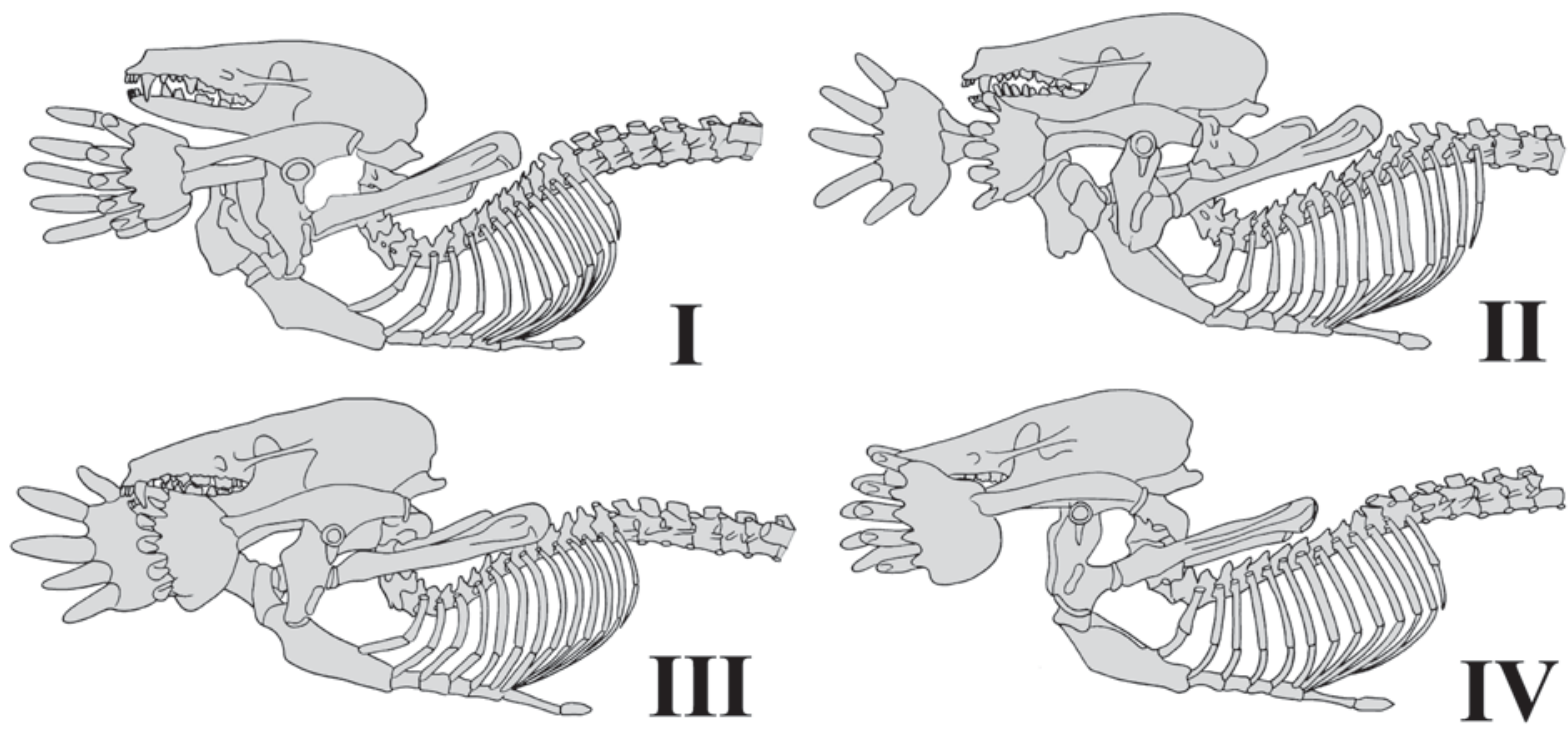

Figure 3. Mole, Talpa europaea, digging in lateral view. Several successive positions (I to IV) of forelimbs drew from the cinefluorographic film taken at 60 frames per second.

rotation of the humerus shifts the medial epicondyle caudolaterally, and the lateral one craniomedially.

Many investigators described the mole skeleton and muscles (e.g., Dobson, 1882; Todorowa, 1927; Edwards, 1937; Reed, 1951; Gambaryan, 1960; Yalden, 1966; Castiella et al., 1992). In some of these works the influence of the burrowing on the structure of the skeleton and muscles was discussed. Sometimes, quantitative parameters of the muscles were taken into account
(Reed, 1951; Gambaryan, 1960). Graphical analysis of static equilibrium (Nikolskii, 1978) revealed the adaptive significance of some structural features in the mole. However, a detailed analysis of the burrowing process has not been undertaken yet. Cinefluorography is the most precise method to study the movements of the skeleton and to analyze muscles functioning. Some fossorial forms have been studied by this method, including Eremitalpa granti (Broom, 1907) (Gasc et al., 
1986), Arvicola terrestris (Linnaeus, 1758) (Laville, 1988), and Myospalax myospalax (Laxmann, 1773) (Gambaryan \& Gasc, 1993). In the present paper we discuss the results of the cinefluorographical study of the burrowing in Talpa europaea.

Despite of the detailed description of muscles in Talpa europaea, the forces, which can be exerted by its forelimbs, are not estimated yet. The aims of our investigation were: 1) to obtain experimental data on the force of pressure of forelimbs in the mole; 2) using the graphical analysis to estimate appropriate internal forces in the forelimb which ensure the necessary force of pressure of the hand against the soil in the lateral thrust; and 3 ) to find out the reason for the adaptive transformation of the skeleton and muscles in the mole associated with its unique burrowing technique. As soon as the mole skeleton and muscles have been described in the literature (Dobson, 1882; Freeman, 1889; Todorowa, 1927; Reed, 1951; Yalden, 1966; Castiella et al., 1992) only additional data on some muscles are provided here.

Abbreviations: m. — muscle; mm. — muscles; p. — pars.

\section{Material and methods}

We study only the burrowing movements, as they have the greatest influence on the adaptive features of the skeleton and muscles in Talpidae. For cinefluorographical analysis, mole was enclosed in a plexiglass box filled with the peat kneaded with water, a substitute for normal soil, which is devoid of mineral particles and is thus permeable to X-rays. The box was wide enough, so that its walls could not restrict the burrowing activity. The animals were filmed either in dorsal or lateral view while digging. The analysis of the kinematics of the limbs is rather complicated: because of the lateral thrust method of digging the limb skeleton moves both in frontal and in parasagittal planes. To solve this problem the syndesmological skeleton was prepared of the individual, which had been filmed. The skeleton was placed in successive positions according to the most typical series of frames filmed in dorsal view. In these positions the skeleton was drawn in both dorsal and lateral views using of the binocular microscope Wild MZ3 (Figs. 1,2). Lateral drawings were adjusted to the frames filmed in lateral view (Fig. 3). However, these lateral frames were not synchronous with the dorsal ones, and therefore, the frames depicted in Figs. 1 and 2 were used for further analysis.

It is known, that a muscle exerts maximum force, while shortening through $30 \%$ of its initial length; further shortening results in quick force decrease (Hill, 1948; Gordon et al., 1966). Therefore we studied the length changes of the muscles during the lateral thrust. Origin and insertion sites of the basic muscles which are presumed to work in burrowing were traced on these figures. If the attachment area is rather large, several points were plotted. For example, there are six points for m. pectoralis superficialis (Fig. 4). The length of muscle (X) was calculated from the formula

$\mathrm{X}^{2}=\mathrm{d}^{2}+\overrightarrow{\mathrm{c}^{2}}$ (Fig. 5)

where (d) is the muscle length measured in the dorsal view frame and $(\overline{\mathrm{c}})$ is the vertical component of its length measured in the lateral view frame. The length changes of the basic muscles were used to find out the best period for force generation.

The force of pressure exerted by the spade-like hands on the substrate was calculated theoretically by adding together the force vectors of individual muscles and the force vectors
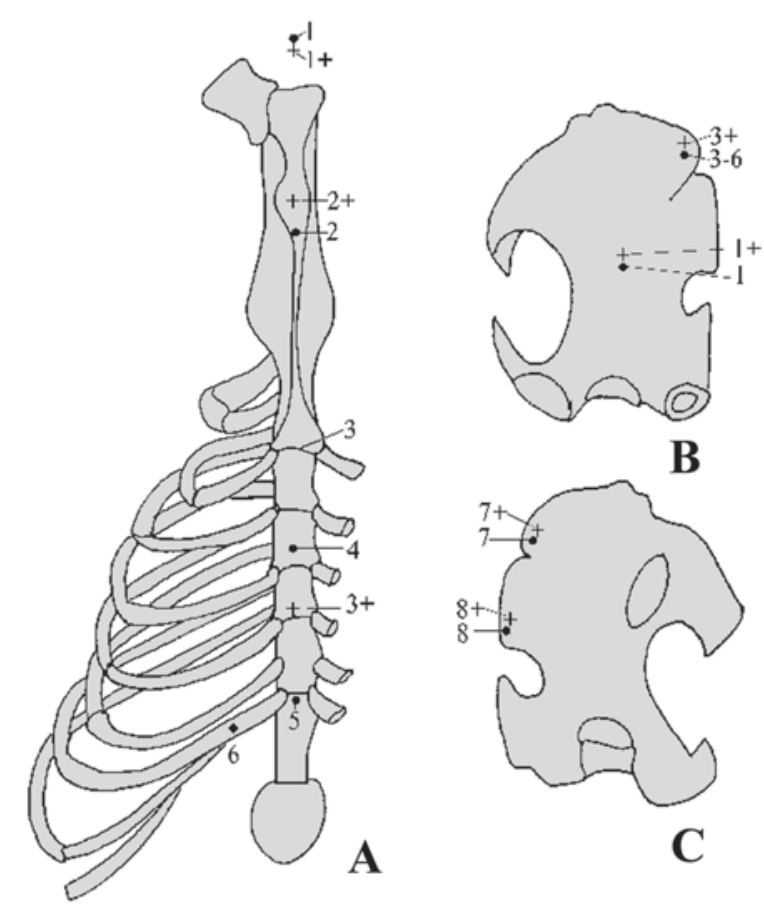

B

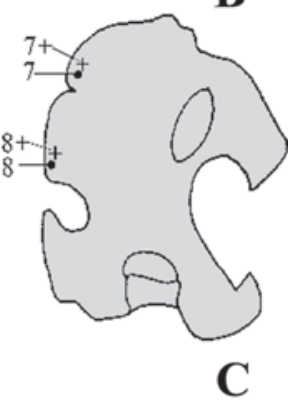

Figure 4. Points of origin and insertion of the forelimb muscles and points of definition of the force moment $(+)$. A - sternum; B and C - humerus in cranial (B) and caudal (C) aspects. $1-6-\mathrm{m}$. pectoralis superficialis $(1,1+-$ p. praesternalis; $2,2+-$ p. manubrialis; $3,3+$ to $5-$ p. sternalis: $3-$ anterior margin; $4-$ intermedial point; $5-$ posterior margin; $6-\mathrm{p}$. costalis); $7-\mathrm{m}$. subscapularis; $8-\mathrm{m}$. teres major.

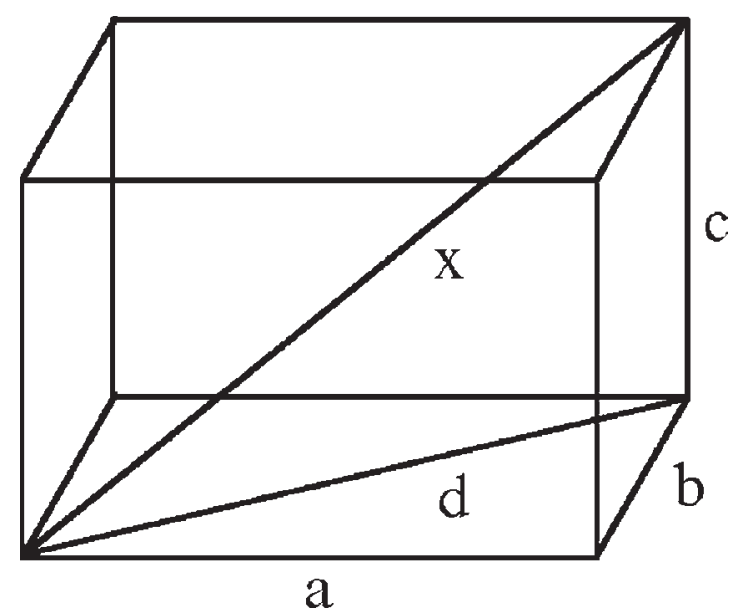

Figure 5. Method to calculate muscle length from measurements made on the frames of cinefluorographical films. $\mathrm{a}$ - parasagittal line; $\mathrm{b}$ - frontal line, $\mathrm{c}$ - vertical line; $\mathrm{d}$ - muscle length projection on the horizontal plane; $\mathrm{X}$ - muscle length.

of their component when they are too wide. Each vector was considered to act along the line connecting the centers of the muscles attachment areas (Fig. 4). Vector length was assumed to be proportional to the muscles physiological cross section. The maximum muscular stress is about $3 \mathrm{~kg} \mathrm{per} 1 \mathrm{~cm}^{2}$ (SchmidtNielsen, 1983). The vectors sum of these muscular forces can 

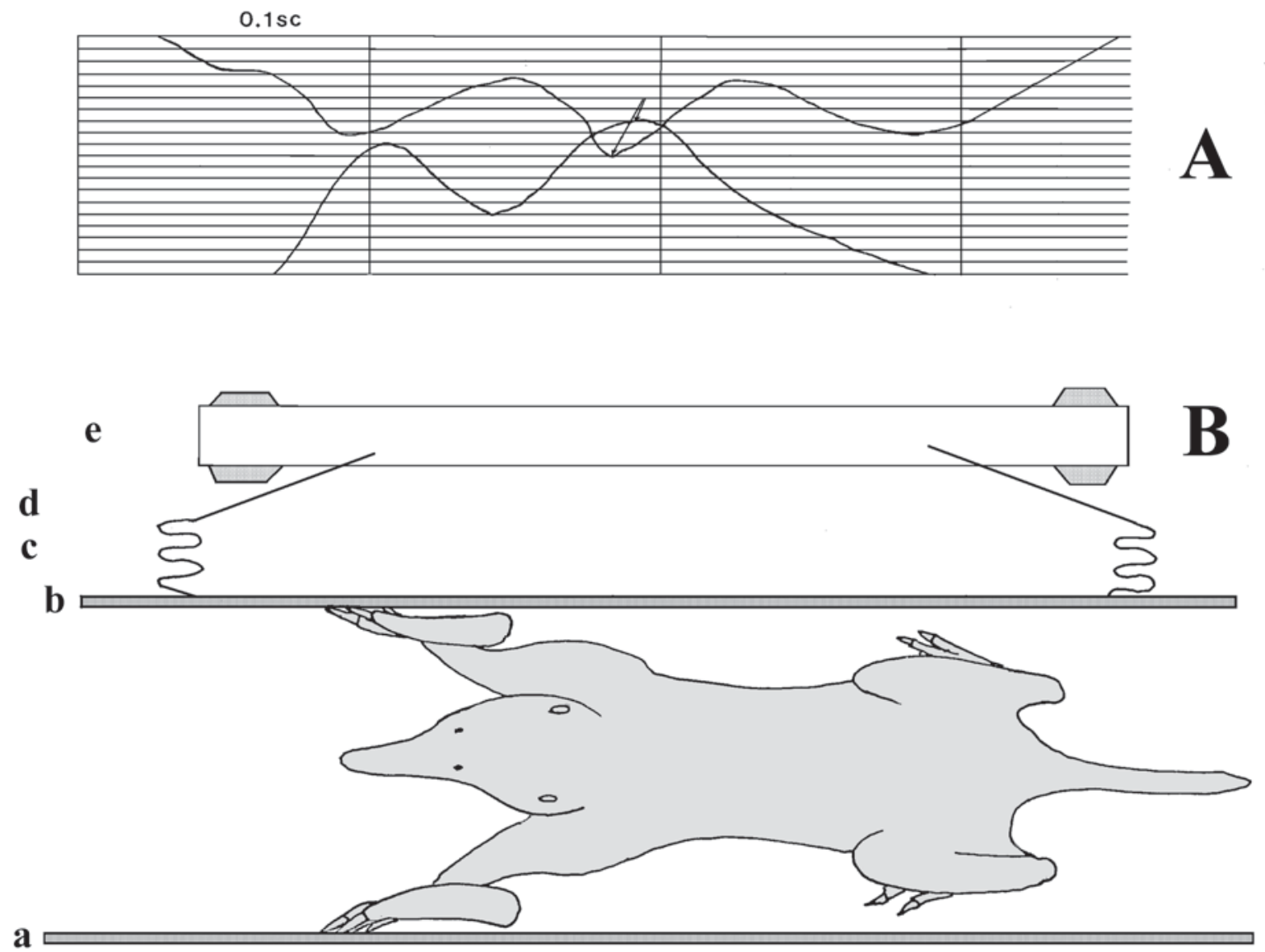

Figure 6. Experimental measurement of the hand pressing force of Talpa europaea.

$\mathrm{A}$ - the dynamic graphs of the pressing force. Horizontal interval equals $100 \mathrm{~g}$; vertical interval equals 0.1 second. Curved lines in A correspond to the force of both forelimbs conveyed by right and left springs. B — the device scheme: $\mathrm{a}$ - immobile wall; $\mathrm{b}$ - mobile wall; $\mathrm{c}$ - two springs (right and left); $\mathrm{d}$ - device measuring the pressing force from each spring on the moving tape (e). The total pressing force of the hands on the mobile wall is obtained by summing the recorder forces (arrows).

be used as the estimate of the pressing force of the hands in the lateral thrust. Similar method was used earlier in the study of Myospalax myospalax (Gambaryan \& Gasc, 1993).

Apart from the theoretical calculation of the hands pressing force, a device was specially designed to estimate this force experimentally (Fig. 6). One wall of this device (a) was immobile, the second (b) was mobile and leaned on two springs (c) connected with a recording apparatus (d) figuring graphically the pressing force from each spring on the moving tape (e). The total pressing force of the hands on the mobile wall of the device is obtained by summing the recorded forces (Fig. 6A). The indicator panel was calibrated with known weights hung from the middle of the mobile wall. The distance between the horizontal line equals to 100 grams. The distance between the vertical line equals to one second.

\section{Results}

Kinematics of the forelimb skeleton during burrowing

Humerus of the mole is flattened and widened. The caput humeri is located on the volar face. The line connecting the center of the caput humeri with that of the throchlea humeri is, according to Freeman (1889), considered to be the longitudinal axis. The line connecting the center of the capitulum humeri with that of the medial epicondyle pit (Fig. 4) is considered to be the transverse axis of the humerus in the distal part (Castiella et al., 1992). During the movement of the forelimb in the lateral thrust, the humerus plane and flexio-extension axis of the shoulder joint are perpendicular to sagittal plane of the trunk. The transversal axis and the flexioextension axis of the elbow joint are inclined to the sagittal plane on the $25-30^{\circ}$ (Fig. 7). This correlation of the flexio-extension axis of the shoulder and elbow joints is called "twisting of the humerus" (Kielan-Jaworowska \& Gambaryan, 1994; Gambaryan \& KielanJaworowska, 1997).

The cinefluorographical analysis of Talpa europaea during burrowing in a homogenous substrate shows that the mole move its forelimbs aside in a symmetrical way (Fig. 8). If the substrate density differs from side to side, the forelimb movement becomes asymmetrical (Fig. 9). The spade shaped hands position, depicted on the Fig. 9, 


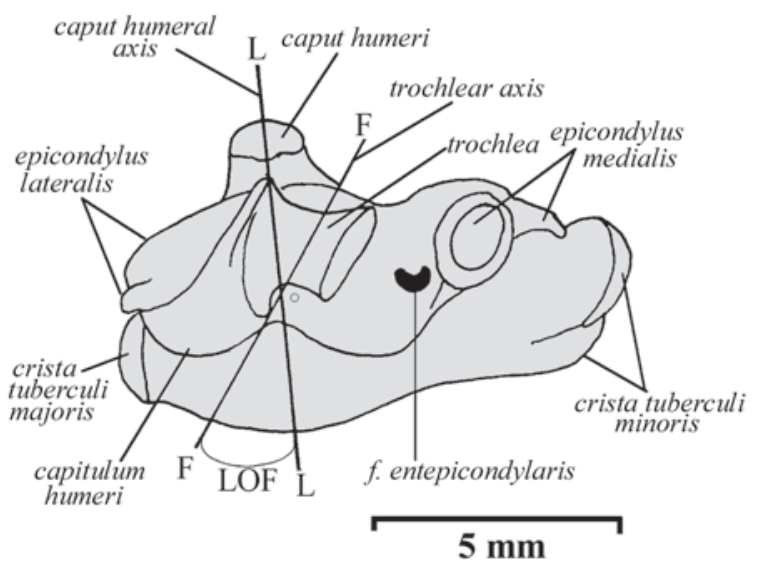

Figure 7. Humerus of Talpa europaea (distal end). LL - flexio-extension axis of the shoulder joint; FF - flexioextension axis of the elbow joint; LOF - twisting angle of the humerus. Abbreviation: f. - foramen.

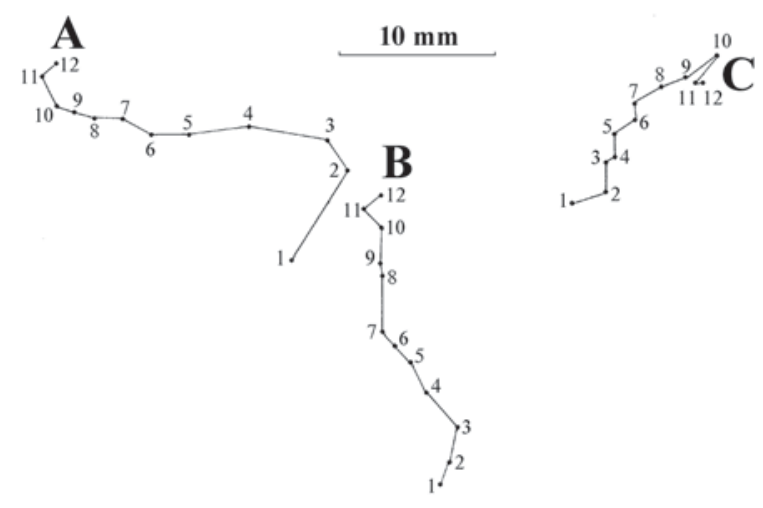

Figure 8 . Trajectory of the right (A) and the left (B) wrist joints and of the anterior end of the manubrium sterni (C) during in lateral thrust in Talpa europaea lasting 12 frames.

The solid line indicates the direction of the displacement of hands inside the ground. The second point corresponds to the frame I, and the twelfth point to the frame VI in Fig. 1.

represents three sequences corresponding to different manners of lateral thrust. The direction of the pressing spade shaped hands can be determined by the displace of two subsequent frames. One can see, that as the direction of the pressing of one hand often did not hit in area of the opposite hand (bearing area) (see Fig. 9A1-2, 2-3, 10 11, 12-13; Fig. 9B1-2, 3-4, 7-8, 9-10, Fig. 9C7 to 12) the other mechanism of the supporting must appear. That can be the support of the hind limbs. The specific structure of the pelvic girdle of the mole is known (e.g., Leche, 1880; Dobson, 1882; Chapman, 1919; Todorowa, 1927; Aburell, 1929). It is evidently connected with the adaptation of the pelvic girdle to the often employment of the hind limbs as the additional supporting mechanism for the lateral thrust. In all of the studied lateral thrust they begin with the hands put forward, at the level of the anterior part of the snout and sometimes even in front of it, the hand volar surface is vertical, with the thumb directed down and the fifth finger upwards.
This is the so called "functional position" (Castiella et al., 1992). The functional position of the hand is kept during the lateral thrust in spite of abduction of the humerus. In the beginning of lateral thrust the clavicle locates on the ventrocranial end of the manubrium sterni (Figs. 1-3). Longitudinal axis of the humerus inclines by $30-35^{\circ}$ to sagittal plane (Fig. 10). The maximum force during the lateral thrust is the force of the abduction of the humerus. It is realized in the sternoclavicular and claviculohumeral joints, and, to a lesser extent, in the shoulder joint. Since the clavicle is short we account movement in two joints as in one - sternoclavicular joint (Fig. 10). For calculation of that scheme we take the vector sum of the forces and determine the moment of the abduction of the humerus for all the frames of the lateral thrust (Fig. 1).

During the lateral thrust the clavicle is gradually displaced in the sternoclavicular joint up to the laterodorsal surface of the anterior end of the manubrium sterni which is exceptionally extended forward in the mole. Its humeral facet moves distally along the clavohumeral joint surface. The noticeable humerus abduction and its rotation together with the scapula are associated with such clavicle movements.

The flexio-extension angles of the shoulder and elbow joints in the most of therian mammals are more than $70^{\circ}$ and $80^{\circ}$, correspondingly. In the mole the maximum angles in these joints (Fig. 11) are less $\left(50^{\circ}\right.$ in shoulder and $55^{\circ}$ in elbow). It has been shown by the cinefluorography of more than 30 cycles digging of the mole that in burrowing these angles reduced till 5-10 . The bended status for shoulder and elbow joints in lateral thrust reduces distance from a sternoclavicular joint up to a hands. This reduces arm of the reactive force by the lateral thrust. As a result the pressure of hands to the soil enhances. And we see that at the end of the lateral thrust, when the maximum pressure on ground is required, the shoulder and elbow joints are really more bend, than in the beginning (compare Fig. 3, I to IV).

The moment of the main abductors enhances when the shoulder and elbow joints are bended (near $90^{\circ}$ ). So the enhance of the moment of the mm. teres major + latissimus dorsi is more than $30 \%$, and of the others abductors is more than $70 \%$ (see Tab. 1).

The force of all the muscles working in a sternoclavicular joint may reach the total value which lead to the detected in experiments (by us and Skoczen, 1958) pressure $2-3 \mathrm{~kg}$ in the hands. We determined the weights and the physiological cross section of the muscles of three moles. In the Tab. 2 the data for the mole (68 g) whose pressing force equals 22 newtons are given. Skoczen (1958) determined the pressing force of the mole $(125 \mathrm{~g})$ in $3 \mathrm{~kg}$.

\section{Musculoskeletal features of the scapular gir- dle and the forelimb}

The humerus abduction is the decisive factor to generate the laterally directed pressure of the spade-like 

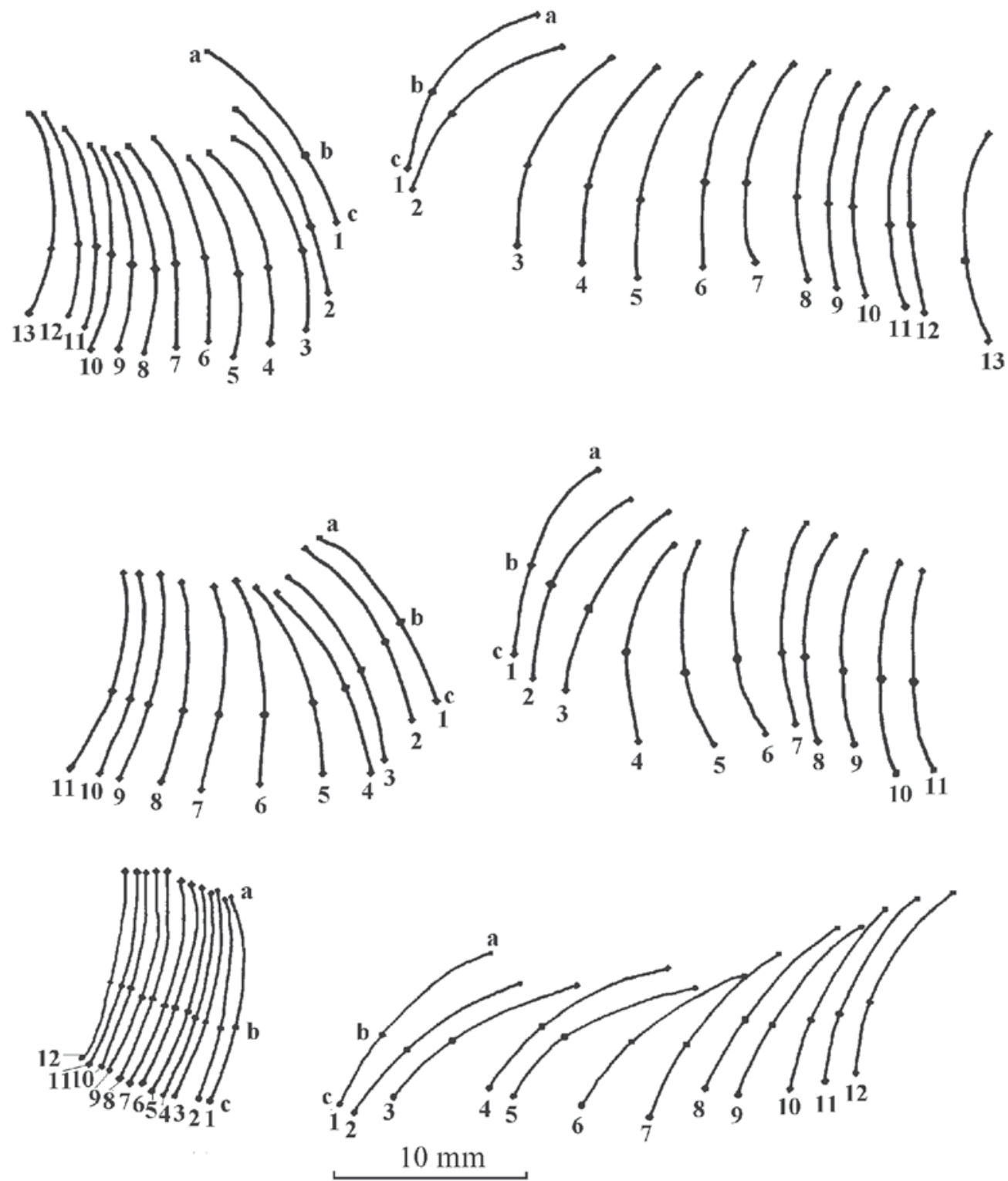

Figure 9. Successive positions of the hands $(a, b, c)$ during three cinefluorographic sequences $(A, B$, and C).

1 to 13 - successive position of volar surface of the hand in the process of burrowing ( $\mathrm{a}$ - nail tip; $\mathrm{b}$ - wrist joint; $\mathrm{c}$ - posterior border of the pressing surface of the hand).

hands on earth (Reed, 1951; Nikolskii, 1978; Castiella at al., 1992). The movement of the scapula, the flexion of the shoulder and elbow joints are coordinated with the humerus abduction. Generally this abduction takes place in the shoulder joint in mammals, whereas in the moles all possible movements in shoulder joint is reduced and abduction takes place in sternoclavicular joint. This limitation is due both to complete congruence of the transverse dimensions of the humerus head within the scapula glenoid cavity (Fig. 12). Therefore all the other possible humerus movements are strongly linked to the scapula ones. Whole abduction in the shoulder joint of the mole is restricted to the $10-15^{\circ}$. The longitudinal axis of the glenoid fossa is directed at angle of $40-45^{\circ}$ to the costal (medial) surface of the scapula (Fig. 13A). In other therian mammals the longitudinal axis of the glenoid fossa usually is parallel to the plane of costal surface of a scapula (Fig. 13B).

In the beginning of the lateral thrust the longitudinal axis of the humerus is directed $25-30^{\circ}$ to the sagittal plane of the trunk (Fig. 10A). The 5-7 $7^{\circ}$ limitation of the abduction of the shoulder joint results in the rotation of the scapula longitudinal axis. The caudal angle of the scapula moves to the sagittal plane. When the humerus begins abduction, the medial surface of the scapula rotates to the parasagittal plane. At the end of the lateral thrust, the slope of the longitudinal axis of the humerus to the sagittal plane is $50-60^{\circ}$ (Fig. 10B). And all 


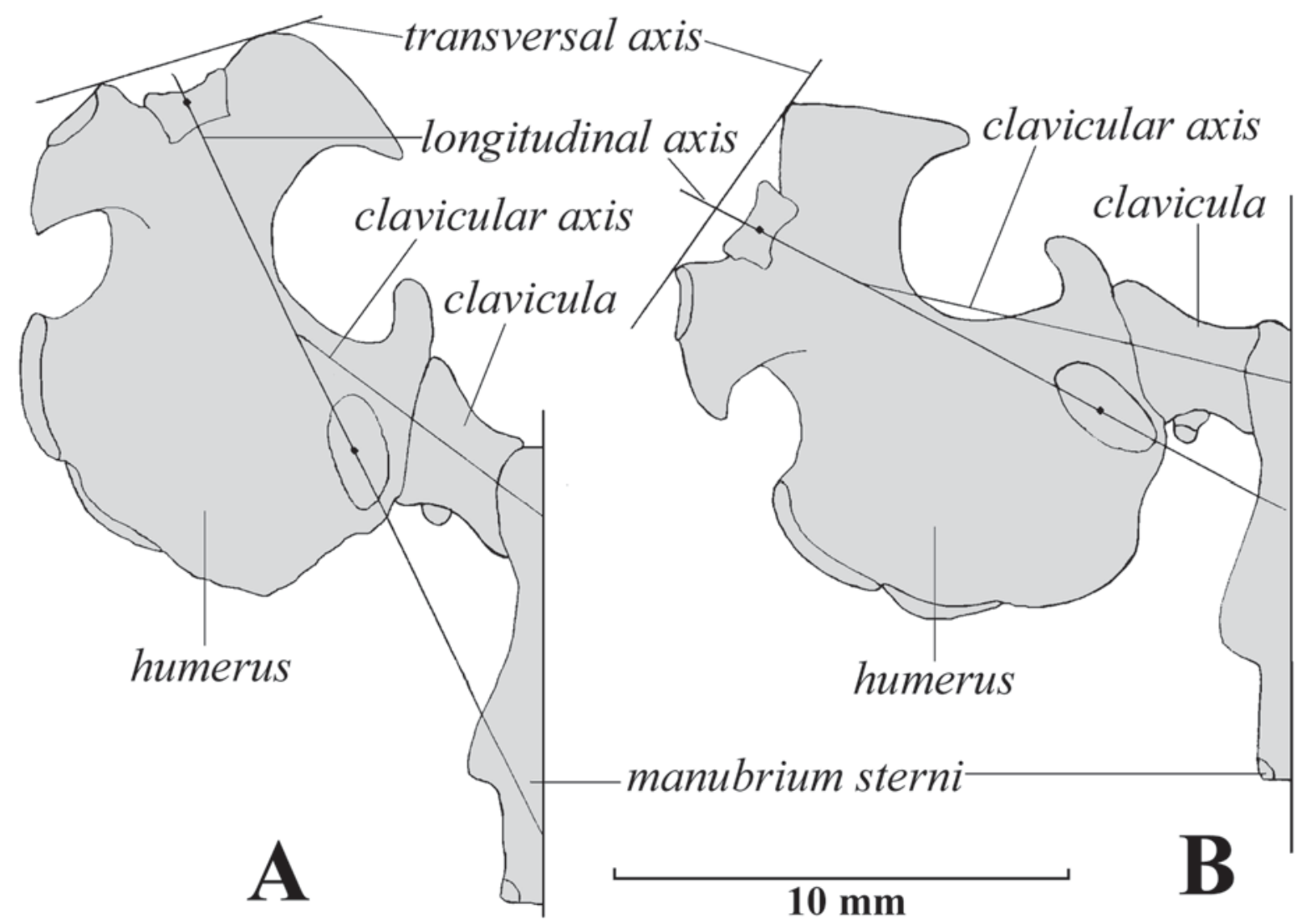

Figure 10. Two positions of the humerus during burrowing in Talpa europaea.

A - beginning of the lateral thrust (corresponds to frame I in Fig. 1); B — end of the lateral thrust (corresponds to frame VI in Fig. 1).

rotation around the longitudinal axis of the scapula is $15-20^{\circ}$ (Fig. 14). When the costal surface of scapula occupies a parasagittal position, the slope of humerus axis to the sagittal plane is about $40^{\circ}$ or even more.

Mm. rhomboideus capitis, rhomboideus cervicis, subclavius p. scapularis, spino- and acromiotrapezius and serratus ventralis provide the scapula movement. This movement is not prevented or restricted with the transverse scapula ligament (homologous with the caudal part of $\mathrm{m}$. rhomboideus thoracis) which is inserts on the little tubercle of the scapula medial surface, where is situated the center of rotation around scapula's longitudinal axis (Fig. 14, O).

This rotation tends to bring the dorsal end of the scapula closer to the sagittal plane causing the humerus rotation and then the medial epicondyle displace to the caudolateral direction. The return of the scapula costal surface to a parasagittal position is accompanied with the humerus abduction.

The muscles of the pectoral girdle and of the shoulder joint take part altogether in this movement. M. serratus ventralis $p$. thoracis of mole is inserted on the lateral termination of the transversal ligament, as distinct from the other mammals (Fig. 14,III,1). M. serratus ventralis p. cervicalis inserted more cranially then former. The force of these two muscles are directed opposite, but the lines of these forces are near the center of rotation therefore their effect is negligible. It is probably that their role is the stabilization of rotation of the scapula. This opinion is confirmed by the unusual position of parts of $\mathrm{m}$. serratus ventralis with wide interval between the insertion. The serratus ventralis $\mathrm{p}$. thoracalis origins on the fourth-sixth ribs, the serratus ventralis p. cervicalis on the processus costotransversarius of third to sixth cervical vertebrae. $M$. rhomboideus $p$. cervicales inserts more lateral than the $\mathrm{m}$. serratus ventralis $\mathrm{p}$. thoracalis (Fig. 14,III,4,3). Usually in mammals these muscles insert on the medial surface of the scapula. M. rhomboideus capitis inserts less cranially than $m$. rhomboideus cervicalis (Fig. 14,III,5). These two muscles turn the cranial angle of the scapula to sagittal plane. The $\mathrm{m}$. subclavius $\mathrm{p}$. scapularis (m. costoscapularis of Howell, 1936) insertion on the pr. acromialis and its function are similar to the function of the two rhomboideus. Only m. spinotrapezius, when inserted on the tuber spinae scapule and $\mathrm{m}$. serratus ventralis $p$. thoracalis rotate the scapula around its longitudinal axis in the opposite direction than the other muscles of pectoral girdle (Fig. 14,I,II). The muscles of 


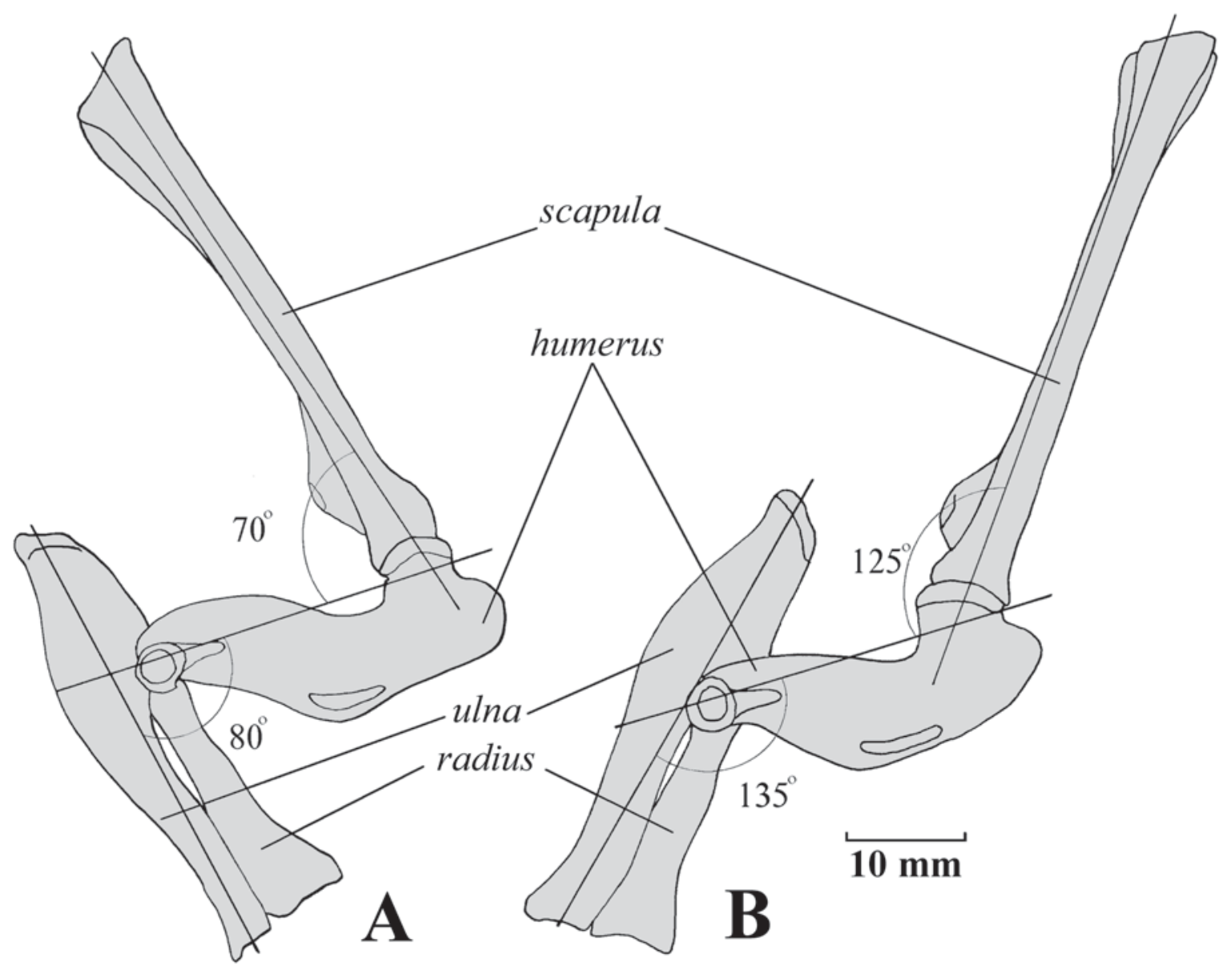

Figure 11. Limits of flexio-extension in shoulder and elbow joints in Talpa europaea. A - maximum flexion; B - maximum extension.

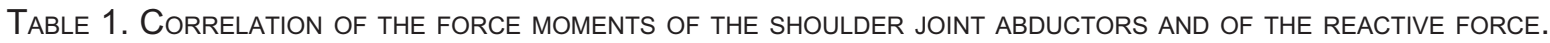

\begin{tabular}{|l|l|c|c|c|c|c|c|c|c|c|c|}
\hline \multirow{2}{*}{} & \multicolumn{3}{|c|}{} & \multicolumn{3}{c|}{ Abduction } & \multicolumn{3}{c|}{ Pronation } & \multicolumn{3}{c|}{ Flexion } & F \\
\cline { 3 - 14 } & & A & B & C & A & B & C & A & B & C & \\
\hline I & 1 & 4.5 & 13.0 & 4.8 & 5.6 & 9.0 & 7.3 & 4.5 & 13.0 & 6.2 & 17.2 \\
\hline II & 1 & 4.0 & 12.0 & 4.4 & 5.0 & 13.6 & 6.4 & 7.5 & 14.0 & 9.2 & 17.2 \\
\hline III & 1 & 4.0 & 21.0 & 3.3 & 5.5 & 12.0 & 7.9 & 4.5 & 22.0 & 3.5 & 17.2 \\
\hline I & 2 & 3.0 & 13.0 & 2.7 & 3.2 & 9.0 & 4.2 & 6.0 & 14.0 & 5.0 & 11.7 \\
\hline II & 2 & 2.0 & 12.0 & 2.0 & 3.5 & 13.6 & 3.0 & 6.5 & 13.0 & 5.9 & 11.7 \\
\hline III & 2 & 2.0 & 21.0 & 1.1 & 3.5 & 12.0 & 3.4 & 3.5 & 22.0 & 1.9 & 11.7 \\
\hline I & 3 & 3.4 & 13.0 & 1.7 & 5.0 & 9.0 & 3.6 & 3.0 & 14.0 & 1.4 & 6.5 \\
\hline II & 3 & 1.8 & 12.0 & 1.0 & 4.8 & 13.6 & 2.3 & 3.2 & 13.0 & 1.6 & 6.5 \\
\hline III & 3 & 1.8 & 21.0 & 0.6 & 4.8 & 12.0 & 2.6 & 3.2 & 22.0 & 0.9 & 6.5 \\
\hline
\end{tabular}

$\mathrm{A}$ - $\operatorname{arm}($ in $\mathrm{mm})$ of the force; B — arm (in $\mathrm{mm})$ of the supporting force; $\mathrm{F}$ - the force in newton; $\mathrm{C}=(\mathrm{A}: \mathrm{B} \times \mathrm{F}) ; \mathrm{I}-\mathrm{begining}$; II end of the lateral thrusth in normal burrowing; III — end of the lateral thrust when the elbow joint is artificialy extended; 1 - mm teres major+ latissimus dorsi; 2 - mm. pectoralis superficialis p. costosternalis + pectoralis profundus; $3-\mathrm{m}$.subscapularis. 

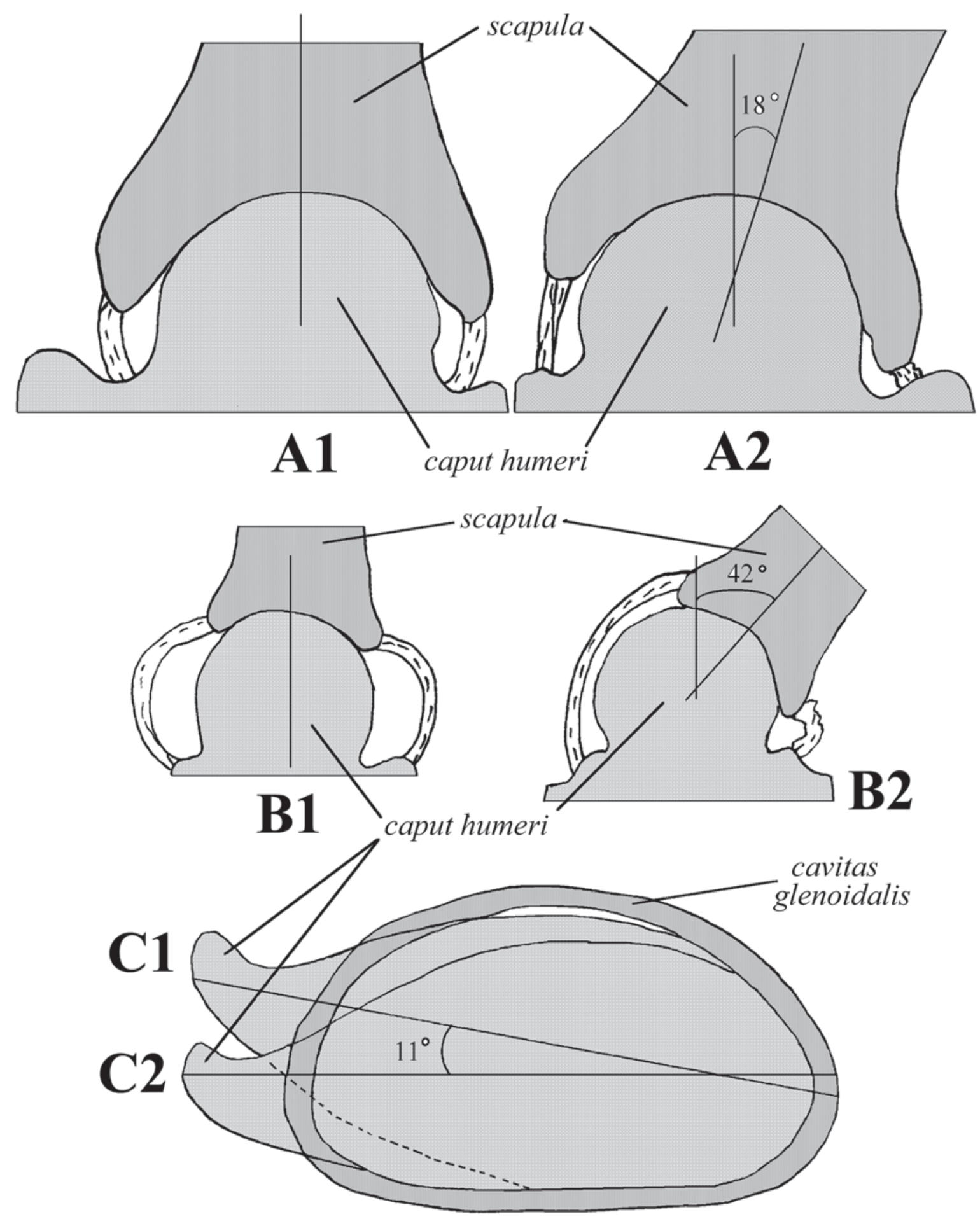

Figure 12. Rotation and abduction-adduction in the shoulder joint.

A, C - Talpa europaea; B - Crocidura sp. A1, B1 - normal position in shoulder joint; A2, B2 - maximum rotation in the shoulder joint; $\mathrm{C} 1$ - maximum abduction; $\mathrm{C} 2$ - maximum adduction.

the shoulder joint: mm. teres major, subscapularis, spinodeltoideus could rotate the scapula, but all these muscles extend in the line of the scapula and only parts of its force can have an influence on rotation of the later.
Mm. pectoralis superficialis, pectoralis profundus, deltoideus p. clavicularis, latissimus dorsi locate in positions responsible for the humerus abduction and extension in the shoulder joint. Their contraction have powerful 
TABLE 2. THE WeIGHT OF THE MUSCLES IN PERCENT TO THE TOTAL WEIGHT OF ALL THE MUSCLES OF THE FORELIMB AND PECTORAL GIRDLE (A).

\begin{tabular}{|l|c|c|l|c|c|}
\hline Muscle & A & B & Muscle & A & B \\
\hline clavotrapezius & 1.32 & 0.07 & anconeus longus & 4.92 & 0.38 \\
\hline spinotrapezius & 1.80 & 0.03 & anconeus lateralis & 1.94 & 0.19 \\
\hline rhomboideus cervicalis & 1.14 & 0.11 & anconeus medialis & 2.15 & 0.22 \\
\hline rhomboideus capitis & 1.48 & 0.06 & epitroch-lateralis & 0.74 & 0.05 \\
\hline latissimus dorsi & 10.55 & 0.20 & leoanconeus medialis & 1.01 & 0.07 \\
\hline sternomastoideus & 0.49 & 0.03 & dorsoepitrochlearis & 0.15 & 0.01 \\
\hline cleidomastoideus & 0.22 & 0.01 & biceps brachii & 1.21 & 0.12 \\
\hline pectoralis p. praesternalis & 2.43 & 0.24 & brachialis & 1.32 & 0.14 \\
\hline pectoralis p. sternalis & 14.11 & 1.06 & pronator teres & 0.92 & 0.11 \\
\hline pectoralis profundus & 1.14 & 0.15 & supinator & 0.02 & 0.01 \\
\hline pectoralis abdominalis & 0.15 & 0.01 & ext. carpi radialis & 0.55 & 0.07 \\
\hline subclavius p. scapularis & 1.85 & 0.28 & ext. digitorum communis & 1.11 & 0.14 \\
\hline subclavius p. clavicularis & 0.62 & 0.06 & ext. digitorum lateralis & 0.25 & 0.03 \\
\hline serratus p. cervicalis & 1,75 & 0.11 & ext. pollicis longus & 0.52 & 0.11 \\
\hline ventralis p. thoracalis & 1.85 & 0.92 & abd. pollicis longus & 0.62 & 0.05 \\
\hline p. accessorius & 0.34 & 0.03 & ext. carpi ulnaris & 0.49 & 0.07 \\
\hline spinodeltoideus & 2.43 & 0.14 & fl. carpi ulnaris & 0.52 & 0.03 \\
\hline clavodeltoideus & 0.74 & 0.11 & palmaris longus & 0.12 & 0.03 \\
\hline supraspinatus & 0,77 & 0.10 & fl. digi-sublimis & 0.28 & 0.05 \\
\hline subscapularis & 8.06 & 0.65 & torum profundus & 0.46 & 0.07 \\
\hline teres major & 28.57 & 1.53 & & & \\
\hline
\end{tabular}

$\mathrm{B}$ - the force in $\mathrm{kg}$.

rotation moment (Fig. 15) around the humerus longitudinal axis. We shall call "pronation" the humerus rotation which brings the medial epicondyle dorsally (caudally), and "supination" the rotation in the opposite direction.

M. pectoralis superficialis has three parts. P. praesternalis and p. manubrialis insert across the humerus from the crista tuberculi majoris to the crista tuberculi minoris. M. clavodeltoideus inserts deeper than these two parts. These two parts of pectoralis superficialis and clavodeltoideus are extensors of the shoulder joint. The third part of the $\mathrm{m}$. pectoralis superficialis - $\mathrm{p}$. costosternalis inserts on the proximal tuberosity of the crista tuberculi minoris (often it is erroneously described as the deltopectoral crest). M. pectoralis profundus and $\mathrm{m}$. pectoralis abdominallis insert together with $p$. costosternalis. These three muscles are important abductors of the humerus. However basic abductors of the humerus are $\mathrm{m}$. teres major, latissimus dorsi and $\mathrm{m}$. subscapu-

Figure 13. Correlation between costal surface of the scapula and longitudinal axis of the glenoid cavity.

A - Talpa europaea; B - Citellus undulatus. goh - angle between costal surface of the scapula and longitudinal axis of the glenoid cavity. Abbreviation: pr. - processus.

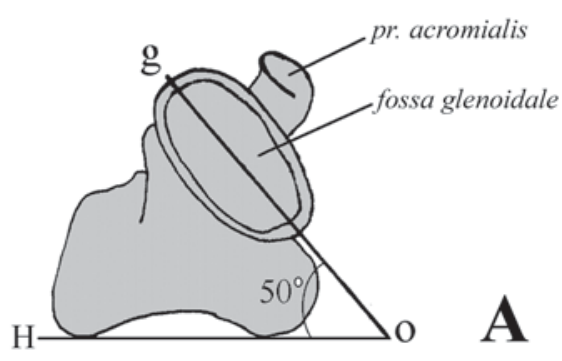

$5 \mathrm{~mm}$

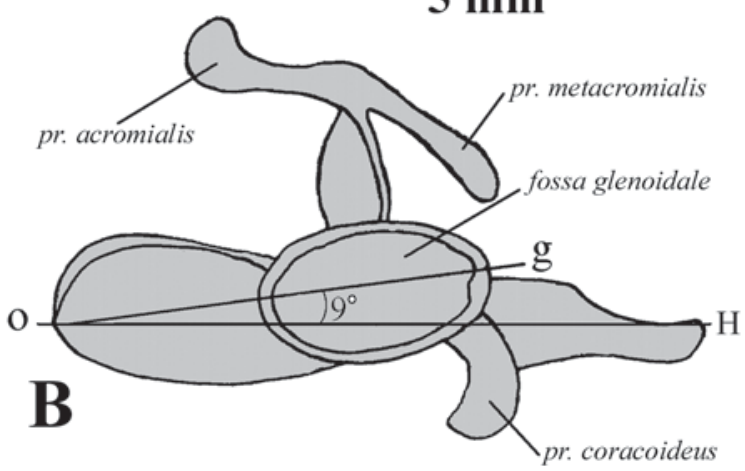




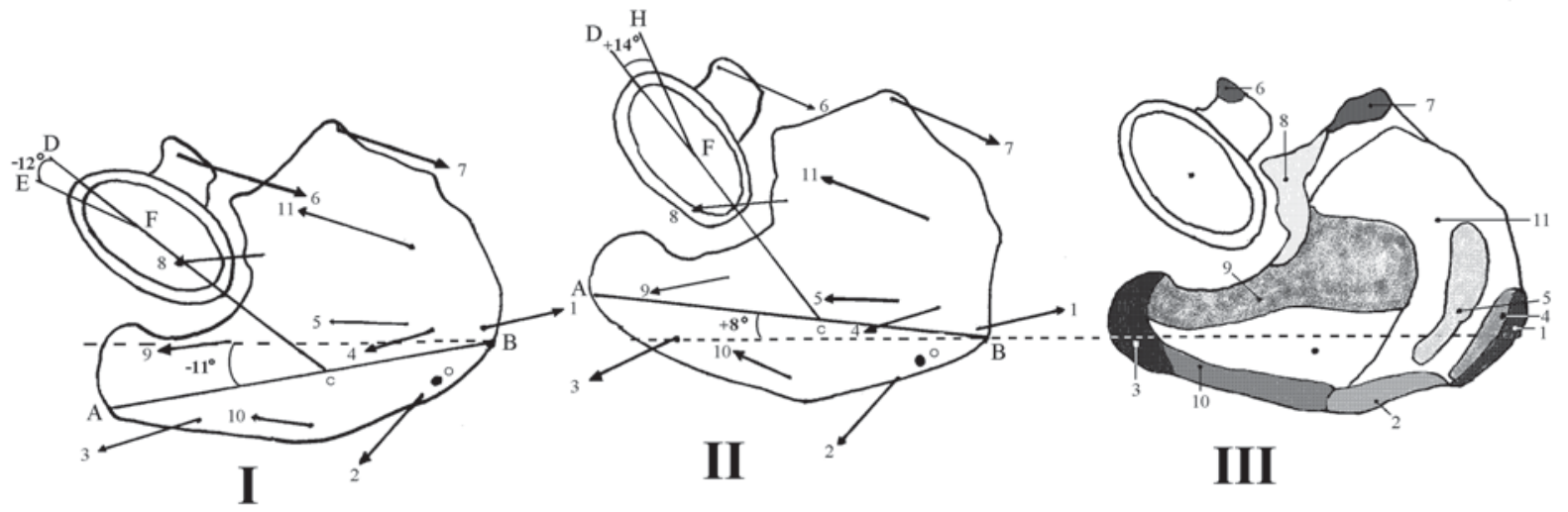

Figure 14. Directions the muscles involved in the rotation of the scapula.

I - beginning of lateral thrust; II — end of the lateral thrust; III - area insertion and origin of the muscles. O — center of the scapula rotation; $\mathrm{AB}$ - costal surface of the scapula; dotted line - parasagittal plane. EF, HF - longitudinal axis of the humerus; EFD+HFD - maximum rotation angle of the scapula; Muscles: $1-3-\mathrm{m}$. serratus ventralis $(1-\mathrm{p}$. thoracalis; $2-\mathrm{p}$. accessorius; $3-\mathrm{p}$. cervicalis); 4 and $5-$ m. rhomboideus $(4-\mathrm{p}$. cervicalis, $5-\mathrm{p}$. capitis); $6-\mathrm{m}$. subclavius p. scapularis; $7-\mathrm{m}$. spinotrapezius; $8-\mathrm{m}$. spinodeltoideus; $9-$ m. supraspinatus; $10-\mathrm{m}$. subscapularis; $11-\mathrm{m}$. teres major.

laris. First two insert together on the distal tuberositi of crista tuberculi minoris. And the last inserts on the proximal tuberositi of crista tuberculi minoris. All these abductors of the humerus are the pronators of the humerus at the same time. However if the humerus should be pronated, the abductors moment of these muscles must decrease. As the abduction of the humerus is the most important function in lateral thrust, there are special adaptations which hinder pronation of the humerus in the mole. Due the topographical and structural peculiarities of $\mathrm{m}$. flexor digitorum profundus its supinating tension increases. This muscle is characterized by the strong tendon which takes its origin in the pit of medial epicondyle and inserted on the claws phalanx of the five fingers. Some weak muscular heads originating from the forearm bones insert on this tendon and regulate its tension (Gambaryan, 1957).

We determine the force which can pull off the tendon of $m$. flexor digitorum away from the medial epicondyle. It equals $5-5.5 \mathrm{~kg}$. Therefore the pressing force of the hands, that equals $2-3 \mathrm{~kg}$ can not pull away that tendon from the medial epicondyle. If the pressing of the spadelike hand increases, the tendon tension grows too, transmitting its supinating action to the humerus. Despite this, the humerus somewhat pronates at the end of the process of moving the soil aside, when the tension of $\mathrm{m}$. flexor digitorum profundus tendon grows up to its maximum extent. Due to their peculiar structure these shoulder joint muscles can only flex it and counteract the abductive efforts of the ground reactive force and the supinating action of the $\mathrm{m}$. flexor digitorum profundus.

As the humerus abducts, flexion of the shoulder and the elbow joints causes an increase of the spade-like hand pressing force, due to reducing of its arm. As the flexion-extension of the shoulder joint does not coincide with the flexion-extension plane in the elbow joint (Fig. 7) flexion and supination result in a lateral displacement of the forearm. As a result the pressing force is in- creased. As the result the reactive force increases too and this additional increase of the force flexes the elbow joint. The elbow joint extensor muscles should act against this reactive force fixing the joint in the most favorable position (Fig. 16).

The elbow joint extensor group in Talpa europaea includes five independent muscles: $\mathrm{mm}$. anconeus longus (triceps caput longum), anconeus lateralis (triceps caput laterale) and medialis (triceps caput mediale), epitrochleoanconeus lateralis (anconeus lateralis) and epitrochleoanconeus medialis. The first one takes its origin from the distal quarter of the scapular caudal border, the following two muscles from the dorsal surface of the humerus. They insert on the top and on the anterior border of the olecranon. The last two muscles take their origin, respectively, from the lateral and medial epicondyles. M. epitrochleoanconeus lateralis inserts on the volar crest of the olecranon down to the elbow joint. M. epitrochleoanconeus medialis inserts on the mediodorsal corner of the olecranon transversal crest. During the simultaneous flexion of the shoulder and elbow joints, $\mathrm{m}$. anconeus longus seems to be in position to counteract the excessive flexion of the elbow joint. The other elbow joint extensors would act when the forearm is perpendicular to the humerus, the ground reactive force increasing noticeably at this moment. In such a case they would act as forearm stabilizators in a position which is the most optimal for burrowing (Fig. 16; Tab. 3).

The arm of force of extensors (length of olecranon) and the arm of reactivity force (length of radius) are such, that the moments of force of $\mathrm{m}$. triceps brachii and reactive force are equalized, that promote resistance to a flexion of a elbow joint. It is interesting to note, that the passive resistance to flexion of a elbow joint allows to reduce the force of extensors of a elbow joint and the length of the olecranon. In the burrowing animals with active extension (unbending) of the elbow joint during 

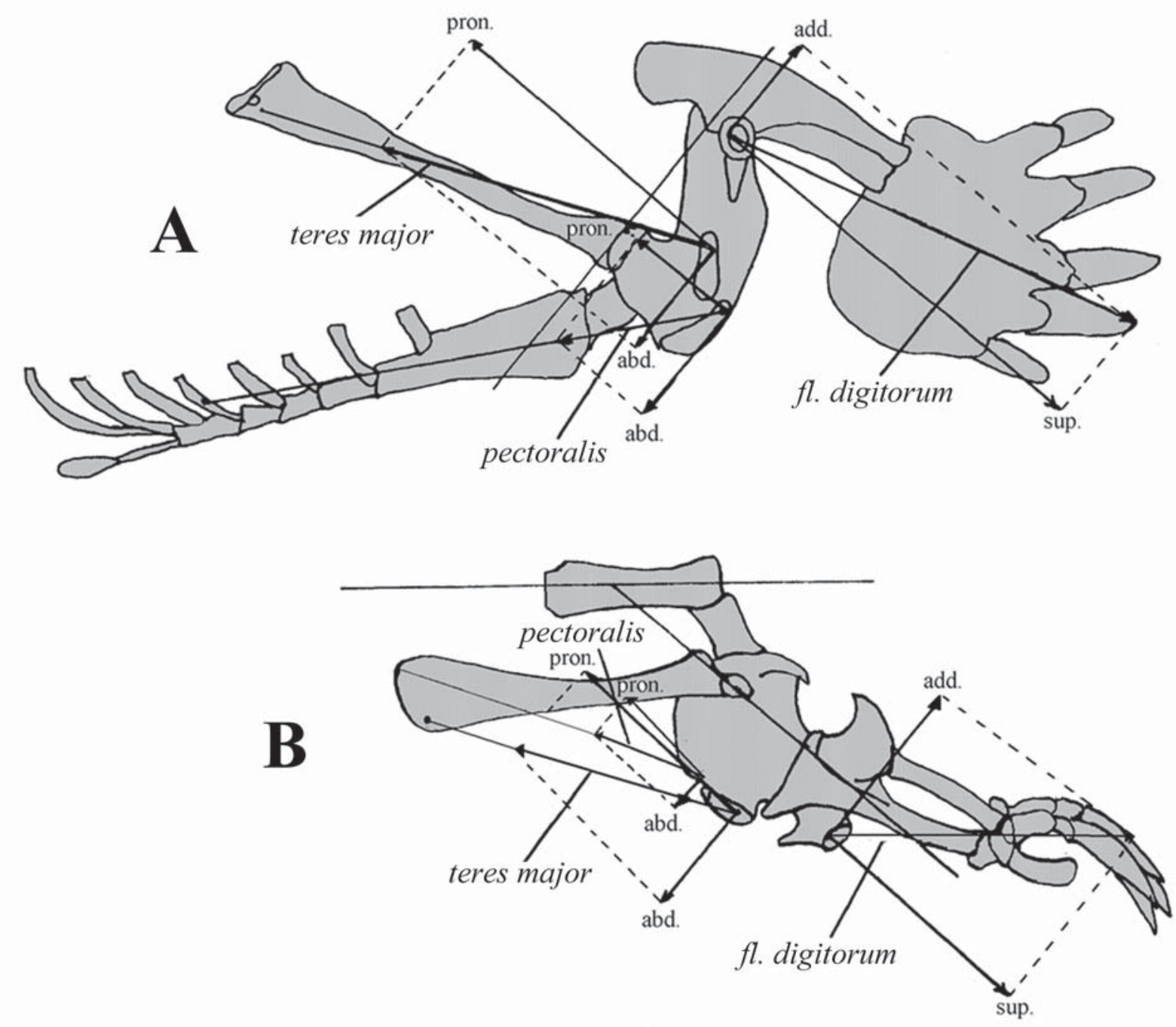

Figure 15. Correlation between of the force of $\mathrm{m}$. flexor digitorum longus and all abductors of the humerus in Talpa europaea. A — lateral view; B — dorsal view. Abbreviations: abd. — abductor component; add. — adductor component; pron. — pronator component; sup. - supinator component.

digging (Spalax, Myospalax), these ratios are much more than in mole (Tab. 4).

It is shown in Tab. 4 that ratio of the length of olecranon to the length of the radius in Talpidae is considerably smaller, than this ratio in specialized burrowing mammals when the extension of the elbow joint is active. But this ratio in the mole is yet greater than in the non burrowing mammals (Crocidura sp., Citellus undulatus (Pallas, 1778)). As regards the comparative mass of the extensor of elbow joint with respect to the mass of all the muscles of pectoral girdle and forelimbs in Talpidae it is smaller not only than in the specialized burrowing mammals but than in the non burrowing mammals too. This correlation is valid even if the mass of $\mathrm{m}$. teres major [the mass of $\mathrm{m}$. teres major give $25 \%$ of the sum of all the muscles of the forelimbs in Talpa europaea and only 3-5\% in the other mammals (Gambaryan, 1960)] would be excluded from the sum of the mass of muscles of the pectoral girdle and forelimbs.
The "functional position" of the hand could not be kept during burrowing in the case of a limited degree of freedom in other joints. In fact, the rotation in the elbowradial joint creates the necessary compensation to maintain the flexion extension axis in the forearm-wrist joint in a parasagittal position (compare Fig. 1, I to VI). This rotation is performed by $\mathrm{m}$. pronator teres which is strongly developed (Tab. 5). The overgrowth of the medial epicondyle increases the rotation moment of this muscle. In addition this moment is increased also by the lateral displacement of capitulum humeri. Usually in mammals the latter one is situated somewhat more laterally than the trochlea is, but in Talpa europaea it is strongly displaced laterally and increases the angle value between $\mathrm{m}$. pronator fibers and the radius. As it has been shown (Tab. 5), pronator muscles relatively enforces in climbing mammals (Glis glis (Linnaeus, 1766), Sciurus anomalus Güldenstaedt, 1792, Pteromys volans (Linnaeus, 1758)), but is still less weak than in moles. 


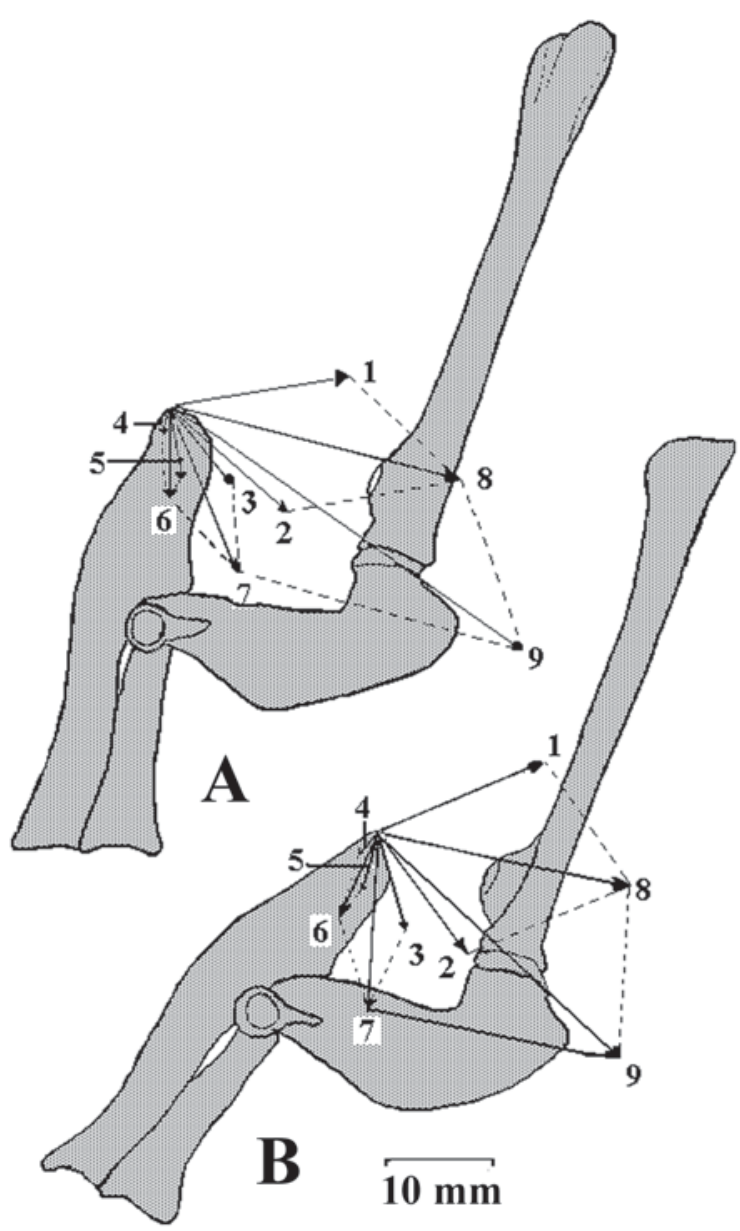

Figure 16. Vectors and its sum for extensors of the elbow joint in Talpa europaea.

A - normal position of the shoulder and elbow joints during the lateral thrust; B - maximum extension in the elbow joint. Muscles: $1-\mathrm{m}$. anconeus longus; $2-\mathrm{m}$. anconeus lateralis; $3-\mathrm{m}$. anconeus medialis; 4 and $5-\mathrm{m}$. epitrochleoanconeus $(4-\mathrm{p}$. lateralis; $5-\mathrm{p}$. medialis).

\section{Dynamics of the basic working muscles}

The variation of the muscles length during the diverse moments of the burrowing movements suggests the respective role of these muscles in the performance of the humerus abduction which is its most important movement (Figs. 1, 10). Mm. latissimus dorsi, pectoralis superficialis p. costosternalis, pectoralis profundus perform the limb abduction at the sternoclavicular joint. Three parts of $\mathrm{m}$. subclavius contribute to its abduction acting at the sternoclavicular joint. Mm. teres major, latissimus dorsi and subscapularis counteract adductional action of the ground reaction force to the limb. The anterior border of $\mathrm{m}$. latissimus dorsi reduces by $39 \%$ of the muscle's length, and the posterior one by $11 \%$. The anterior border of $\mathrm{m}$. pectoralis profundus reduces by $15 \%$, and the posterior by $17 \%$. M. pectoralis superficialis, which is one of the main shoulder adduc-
TABLE 3. THE CORRELATION OF THE MOMENTS OF THE EXTENSOR MUSCLE FORCES AND THE SUPPORTING FORCE

IN ELBOW JOINT.

\begin{tabular}{|l|c|c|c|c|}
\hline Muscle & A & F & I & II \\
\hline anconeus longus & 0.4 & 3.82 & & \\
\cline { 1 - 3 } anconeus lateralis & 0.4 & 3.38 & & \\
\cline { 1 - 3 } anconeus medialis & 0.4 & 2.18 & \multirow{2}{*}{9.4} & \multirow{2}{*}{7.2} \\
\cline { 1 - 3 } epitrochleoanconeus lateralis & 0.35 & 1.5 & & \\
\cline { 1 - 3 } epitrochleoanconeus medialis & 0.4 & 0.65 & & \\
\hline
\end{tabular}

A - ratio of the length of the olecranon to the length of the radius; $\mathrm{F}$ - force of the muscle in newtons; the total pressing force of all the extensors in I - normal position of the elbow joint $\left(90^{\circ}\right)$ and II - a hypothetical position of the elbow joint $\left(120^{\circ}\right)$.

Table 4. Correlation between the arm of force of THE ELBOW JOINT EXTENSORS AND THE COMPARATIVE WEIGHT OF THE MUSCLES OF THE ELBOW JOINT.

\begin{tabular}{|l|c|c|}
\hline Taxon & A & B \\
\hline Talpa europaea & 0.5 & 10.9 \\
\hline Mogera robusta & 0.5 & 11.0 \\
\hline Condylura cristata & 0.4 & 11.8 \\
\hline Scalopus aquaticus & 0.5 & 11.1 \\
\hline Neurotrichus gibbsii & 0.3 & 10.9 \\
\hline Crocidura sp. & 0.2 & 17.0 \\
\hline Nannospalax nehringi & 0.6 & 20.8 \\
\hline Spalax microphtalmus & 0.6 & 21.2 \\
\hline Spalax giganteus & 0.7 & 21.7 \\
\hline Myospalax myospalax & 0.8 & 22.0 \\
\hline Geomys bursarius & 0.6 & 18.1 \\
\hline Citellus undulatus & 0.2 & 17.0 \\
\hline
\end{tabular}

$\mathrm{A}$ - ratio of the olecranon length to the radius length; $\mathrm{B}$ - ratio of the weight of the elbow joint extensor percent to the total weight of all the muscles of the pectoral girdle and forelimbs.

tors, divides into three independent parts. Right and left p. praesternalia mend with their bases in front of the manubrium sterni anterior edge and insert on the humerus dorsal surface across to the crista tuberculi majoris and minoris more superficially than $\mathrm{m}$. clavodeltoideus. P. praesternalis reduces by $27 \%$ during almost all the process of burrowing and up to the end it lengthens by $8 \%$ of its original length (Fig. 17). P. anterior takes its origin from the manubrium sterni and inserts to the crista tuberculi minoris; the anterior border of the part reduces by $28 \%$ (Fig. 1, frame V) and then by $8 \%$ more (Fig. 1 , frame VI), total shortening being 36\%. The posterior border of the part reduces, respectively, by $30 \%, 16 \%$ and $46 \%$. P. intermedius takes its origin from I-II sternal segments and inserts together with the preceding portion; the anterior border of $\mathrm{p}$. intermedius at first reduces by $39 \%$ (Fig. 1 , frame V), then by $13 \%$ more (Fig. 1 , frame VI), total shortening being $51 \%$; the posterior 
Table 5. Weight of the M. PRonator teres (A) IN PERCENTS TO THE TOTAL WEIGHT OF ALL THE MUSCLES IN THE FOREARM.

\begin{tabular}{|l|c|}
\hline Taxon & A \\
\hline Talpa europaea & $15-16$ \\
\hline Mogera robusta & $14-15$ \\
\hline Condylura cristata & 17.9 \\
\hline Scalopus aquaticus & 30.8 \\
\hline Neurotrichus gibbsii & 12.9 \\
\hline Desmana moschata & 14.2 \\
\hline Crocidura sp. & 6.2 \\
\hline Xenarthra, four species & $3-5$ \\
\hline Glis glis & $10-11$ \\
\hline Pteromys volans & $7-8$ \\
\hline Sciurus anomalus & $7-8$ \\
\hline Citellus, three species & $4-6$ \\
\hline Marmota, three species & $5-6$ \\
\hline Muridae, five species & $3-6$ \\
\hline Cricetidae, six species & $3-5$ \\
\hline Spalacidae, four species & $3-4$ \\
\hline
\end{tabular}

border reduces, respectively, by $20 \%, 17 \%$ and $37 \%$. P. posterior spreads from the third segment of the sternum till the base of the xiphisternum and the costal cartilages of fourth-eighth ribs. It inserts more distally than the preceding muscles. Up to the frame $\mathrm{V}$ the anterior border of the portion reduces by $28 \%$, and up to the frame VI by $15 \%$ more, total shortening being $43 \%$. The posterior border of the costal and sternal parts reduce by $23 \%$ (Fig. 1 , frame V) and then by $12 \%$ (Fig.1, VI), total shortening being $35 \%$.

All the investigators who studied mole burrowing mechanisms (e.g., Freeman, 1889; Todorowa, 1927; Campbell, 1939; Reed, 1951) told that, when the hands are moved aside, the mole straightens its forelimbs forward, extending the shoulder and the elbow joints and rotating the shoulder so as to fix the humerus plane in parasagittal position. A graphical analysis of static equilibrium of such a skeletal movement was performed by Nikolskii (1978). In contrast, our data show that the shoulder and elbow joints was always flexed, thus reducing noticeably the resisting force lever arm. Due to this lever shortening, the mole could make an effort more than $2 \mathrm{~kg}$ when the muscles responsible for the removing of soil act together (Tab. 3).

A muscle is known to create the maximum force when it shortens by no more than $30 \%$ of its resting length; further shortening results in sudden force decrease (Gordonet al., 1966). One can see that in the mole the independent parts of $\mathrm{m}$. pectoralis superficialis contract mainly in optimal way (Fig. 1, frame V). It is interesting to note that despite of the continuing shortening of the shoulder abductors (Fig. 1, frame VI) the limbs

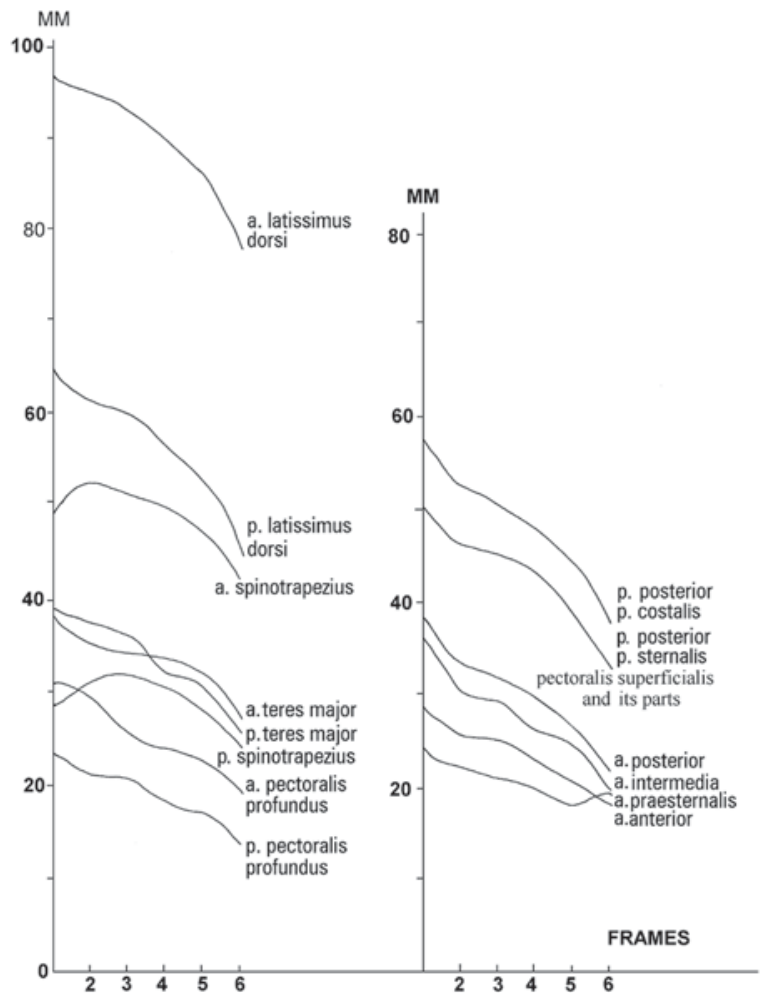

Figure 17. Length change of the muscles and their parts during burrowing in Talpa europaea.

cannot counteract the ground reaction force anymore (Fig. 8). Seemingly, not only the firmly packed soil prevents further moving but also the main shoulder adductors force has decreased because of the muscles extra shortening.

M. spinotrapezius takes its origin from the spinal processes of the last three pectoral vertebrae and from the metapophyses of the first three lumbar vertebrae and inserts to the tuber spinae scapulae. This muscle lengthens by $2-5 \%$ and then reduces by $11-12 \%$ of its original length (Fig. 17). M. teres major is the strongest muscle in the mole, its mass ratio is $25 \%$ in relation to the mass of all the other muscles of the anterior girdle and of the forelimb. It takes its origin from the caudal border of the shoulder-blade and inserts to the special crest of the shoulder bone medial border. This muscle like m. pectoralis superficialis contracts in an optimal way reducing by $18-21 \%$ as one can see on the first five frames (Fig. 1 ), and by $32-35 \%$ up to the frame VI.

In fact one can suggests that when the action of removing the earth with the forelimbs begins, the pressing force from the spade-like hands to the substrate is minimal and at the same time all the humerus abductors develop the maximum force because they work in the optimum regime. But as far as the earth moves apart the force of reaction must increase and the instant comes when the muscles cannot remove the soil. The reaction force is maximum at that very instant but the force of all the abductors decrease because they do not work in the 
optimum regime now: their shortening exceed the $30 \%$ limits of the optimal regime of the muscles contraction. In our experiments the peat kneaded with water was elastic. Perhaps this explains the movement of the hands little back on the end of the lateral thrust (Fig. 8).

The point of application of the summary force (Fig. $1, A)$ usually lies between the crista tuberculi minoris and caput humeri. We showed that the summary momentum of the humerus abductors remains nearly constant during the lateral thrust (Fig. 1, A). But the pressing forces depend on their direction and on the position of the forelimbs. Three directions of the pressing force was studied: $60^{\circ}, 90^{\circ}$, and $120^{\circ}$ to volar surface of the hand (Fig. 1). Only by $90^{\circ}$ the support can be transmitted from one hand to the other. Two other dispositions are possible only by the support on the other parts of the mole (hind limbs, trunk). One can see that to the end of the burrowing cycle when the pressing force is directed forward and lateral it increases markedly. Perhaps the movement of the forearm wrist joint rather forward than lateral is conditioned by this increase.

\section{Discussion}

The Cinefluorographical study of Talpa europaea burrowing not only enabled us to analyze the skeleton kinematics but also gave new data to discuss some peculiarities of the animal's digging activity. One of the most important moments of digging activity in highly specialized burrowing animals is the way in which they throw the loosened earth out of a tunnel. The description of the mode of throwing out the earth made by Formozov (1952) seems to be wrong. He considered that the moles and the mole-rats (Spalax) push the earth out of tunnel with the head which is used as a spade, while they are leaning with their limbs against tunnel walls. In fact, such an action with the aid of the head is the widespread mode in highly specialized burrowing animals. It is characteristic of the many burrowing mammals: Notoryctes typhlops (Stirling, 1889) (Marsupialia); Chrysochloridae (Afrotheria); Spalacidae and Myospalacidae (Rodentia), Chlamyphorus trucnatus Harlan, 1825 (Xenarthra). All that burrowers mentioned have some morphological adaptations to strengthen the skull and to widen the dorsal surface of the head. Their nasal bones have been fused, and maxillary bones thickened, and the special horny nasal patch has appeared on the dorsal surface of the snout end. The snout itself is widened due to special lateral folds consisting of skin and muscles. There are no such features in the family Talpidae.

The analysis of X-ray films disclosed that the mole acts with its spade-like hands when lifting up the loosened soil particles. The hind limbs and the posterior part of the trunk still keep their normal posture whereas the forelimbs and the pectoral part of the trunk are turned at right angles in respect to the posterior part of the body. Therefore, the moles push out the earth and make the mounds with their forelimbs, the movement being exactly the same as in burrowing. Quite similar method of the displacement of the earth were observed in the eastern American mole Scalopus aquaticus (Linnaeus, 1758) (Hisaw, 1923).

A theoretical calculation of the force pressing on the hands may be done in both cases: when the forelimbs are straightened and when they are flexed. It appeared that in the former case the hands pressing force cannot amount to the maximum value determined in experiment [2 kg (our experiments) or $3 \mathrm{~kg}$ (Skoczen, 1958)].

The question on turning around the shoulder plane which resulted in the fixation of the later in parasagittal position was discussed in literature (Todorowa, 1927; Campbell, 1939; Reed, 1951) and needs to be mentioned about especially. In such a position the expanded crest of the crista tuberculi minoris of humerus to which $\mathrm{mm}$. teres major, latissimus dorsi, pectoralis and subscapularis insert would not be in an optimal position to generate a significant abductive effect. In contrast, the fixation of the humerus in a position perpendicular to sagittal plane at the end of the process of removing the earth increases the abductive effect of these muscles.

Cinefluorography revealed that for both hands the lines of action of the pressure on one hand cross the area of the pressure of the other one. However, it happens rather often that the direction of the pressure of one hand misses the area of the pressure of the second hand creating an unbalanced condition which would yield a lateral thrust of the animal. Continuation of the movement implies that some other mechanisms are acting . The hind limbs are firmly planted into the ground and their longitudinal effort is transmitted through the vertebral axis to the forelimbs. The peculiar construction of the pelvic girdle and the hind limbs in the mole could be related to this need for a supplementary action.

For comprehension of the reason of the mole's humerus reorganization we propose the scheme of the interrelation of the humerus and m. pectoralis (Fig. 18 ). The direction of the attraction of the $\mathrm{m}$. pectoralis bundles are given in this scheme for two position: for the usual humerus position (1), which is typical for terrestrial mammals and for the mole's ancestor, and for the humerus directed forward (2). The sternum of the nonburrowing mammals is given on Fig. 18A and on Fig. $18 \mathrm{~B}$ the manubrium sterni is typical for the moles. One can see that by the usual ending $\mathrm{m}$. pectoralis adducts and retracts the humerus. By the normal locomotion of the terrestrial mammals this action of the $\mathrm{m}$. pectoralis is neutralized by $\mathrm{mm}$. spinodeltoideus and infraspinatus and the forelimb moves in the parasagittal plane. But in order to throw away the soil the humerus must abduct. The abduct of the humerus is possible by the anatomically medial displacement of the $\mathrm{m}$. pectoralis end (for the hyperabducted humerus the displacement is in fact lateral). The displacement of the $\mathrm{m}$. pectoralis end is represented (Fig. 18B) by the dotted line outgrowth. The mole's humerus is placed at the level of the end of the lengthened manubrium sterni. By such configuration the $\mathrm{m}$. pectoralis $\mathrm{p}$. costosternalis with the medial displacement of its end becomes the humerus abductor. 

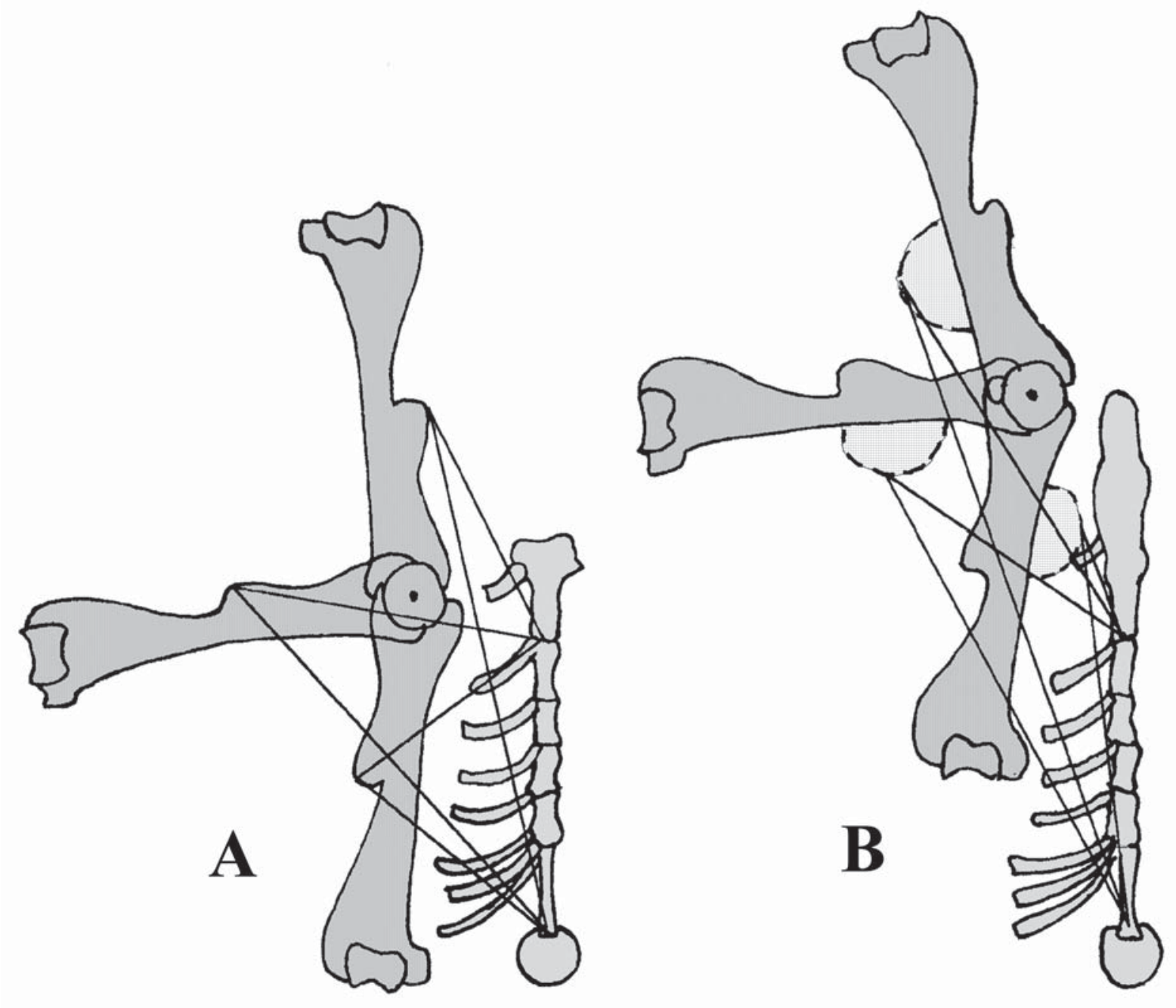

Figure 18. Two ways of widening of the humerus in mammals.

A - normal and hyperabduction position of the humerus is in not burrowing mammals where the manubrium sterni is of normal length; B same position of the humerus with manubrium sterni similar to that in the mole. Dotted line denotes hypothetical widening of the humerus in medial region, where $\mathrm{m}$. pectoralis is inserted.

The pressure on the soil is enhanced with the shortening of the force's lever. This shortening is especially actual in view of the decrease of the pressure at the enlargement of the hand which is desirable for the enhancement of the amount of the moved away earth.

The shortening of the force's lever can be realized either by the reduction of all segments of the forelimb or by the reduction of the distance on the whole due to their optimal arrangement. But in any case for all that it is necessary to shift the forelimb to the head in order to make light the soil in front of the mole's muzzle. This is realized by the lengthening of the mole manubrium sterni. The hyperabduction of the humerus is accompanied by the hyperextension of the shoulder joint. As a result the humerus is situated nearly upright during the digging. This arrangement of the humerus brings with it the slope of the scapula. Its dorsal range remainsalmost in the same position which is typical for the terrestrial mammals.
And the ventral range of the scapula moves forward in proportion to the manubrium sterni lengthening.

The widening of the humerus and especially of its medial range is an important adaptation to the abduction of the forelimbs - the main function by the earth rejection. Most of the investigators (e.g., Todorowa, 1927; Reed, 1951; Yalden, 1955) assumed the disposition of the humerus in the parasagittal plane to the end of the lateral thrust and its pronation around the longitudinal axis in order to reach this position. However our investigations revealed that the humerus plane never coincide with the parasagittal plane. The parasagittal disposition of the humerus is very unfavorable for the main humerus abductors as the action lines of the mm. teres major, latissimus dorsi, subscapularis, pectoralis lay on the humerus longitudinal axis. The absence of the abductor momentum neutralized entirely the advantage of the humerus widening. On the contrary when the humerus plane is perpendic- 
ular to the parasagittal plane the abductor momentum of these muscles is maximal. In order to secure the parasagittal disposition of the hand the twisting of the humerus developed secondary in moles. The same purpose is favored by the changes in the elbow joint - the convexity and the appreciable narrowing of the articular surface of the ulna let its rotation around the longitudinal axis. The rotation of humerus is limited by the $m$. flexor digitorum profundus. The ligament of this muscle connects the five claws and the medial epicondyle. And the strengthening of the hand pressure on the earth automatically increases the forces which hinder the rotational momenta of the shoulder's abductors. The larger is the humerus abduction (the actions of the $\mathrm{mm}$. teres major, subscapularis, pectoralis and latissimus dorsi) the stronger is the $\mathrm{m}$. flexor digitorum profundus ligament strain. All these can be regarded as the special mechanism which act against the humerus rotation.

It is interesting to note that the humerus width of the cynodonts, the ancestors of the primary mammals, and of the recent Monotremata is not less than in moles. The main function of the so wide humerus was its rotation which lengthened the step by the terrestrial locomotion (see Jenkins, 1970; Pridmore, 1985). At the same time they have the special devices which limit the humerus abduction (retraction). Their supinators ( $\mathrm{mm}$. supraspinatus and infraspinatus) hinder the humerus abduction.

It is interesting that the convergence with the return to the wide humerus in the moles is the result of the principally different functional requirements. For the primary wide humerus this is the adaptation to the marked rotation $\left(40-60^{\circ}\right.$, Pridmore, 1985$)$ by the limited abduction and by the twisting which is needed in order to retain the horizontal position of the hands by the locomotion with the extended limbs. For the wide humerus of the moles this is the adaptation to its maximum abduction by the limited rotation and by the secondary appeared twisting asked for the parasagittal position of the hands during the lateral thrust.

Thus the widening of the humerus proximal end increases the abductor momentum necessary for the main active action within the lateral thrust of the moles namely the action of the pulling out the earth. The widening of the medial epicondyle increases the strain of the $\mathrm{m}$. flexor digitorum longus ligament which hinder the humerus rotation. As to the humerus rotation, it reduces the abductor momenta of the $\mathrm{mm}$. teres major, subscapularis, pectoralis and latissimus dorsi the main muscles which ensure the lateral thrust force. The widening of the olecranon top with the appearance of the medial and lateral tubercles on it as well as the widening of both humerus epicondyles prevent from the dislocation of the elbow joint during the lateral thrust.

The active extension of elbow joint in non-burrowing mammals and, especially, in some burrowing mammals (Spalax, Myospalax) lead to the vigorous elbow joint extensors. But the function of these muscles in the moles is the passive resistance to the elbow joint flexion. As a result the force of the elbow joint extensors in moles are relatively decreased.
Specific features of the hind limbs and the pelvic girdle of the moles are the adaptations to support during the lateral thrust when the direction of the pressure of one hand misses the area of the pressure of the second hand.

\section{References}

Aburell M. E. 1929. Contribution à l'anatomie du bassin de la Talpa europaea L. // Bulletin du Muséum national d'Histoire naturelle. Séries 2. No.1. P.292-297.

Campbell B. 1939. The shoulder anatomy of the moles. A study in phylogeny and adaptations // American Journal of Anatomy. Vol.64. No.1. P.1-39.

Castiella M.J., Laville E., Renous S. \& Gasc J.-P. 1992. Caracteristiques morphologiques du membre anterieur de la taupe commune, Talpa europaea (Mammalia, Talpidae) // Mammalia. T.56. No.2. P.265-285.

Chapman R.N. 1919. A study of the correlation of the pelvic structure and habits of certain burrowing mammals // American Journal of Anatomy. Vol.25. No.2. P.185-219.

Dobson G.E. 1882. A Monograph of the Insectivora, Systematics and Anatomy. London: P.I. John Van Voorst. 172 p.

Edwards L.F. 1937. Morphology of the forelimb of the mole (Scalopus aquaticus) in relation to its fossorial habits // Ohio Journal of Science. Vol.37. No.1. P.20-41.

Formozov A.N. 1952. [Companion of a Pathfinder]. Moskva: Moskovskoe Obshchestvo Ispytatelei Prirody. 360 p. [in Russian].

Freeman R.A. 1889. The anatomy of the shoulder and upper arm of the mole (Talpa europaea) // Journal of Anatomy and Physiology. Vol.20. No.2. P.201-219.

Gambaryan P.P. 1957. [On the pinnated muscles function] // Doklady Akademii Nauk Armyanskoi SSR. T.5. No.1. P.87-91 [in Russian].

Gambaryan P.P. 1960. [Adaptive Features of the Locomotory Organs in Fossorial Mammals]. Erevan: Izdatel'stvo AN Armyanskoi SSR. 195 p. [In Russian].

Gambaryan P.P. \& Gasc J.-P. 1993. Adaptive properties of the musculoskeletal system in the mole-rat Myospalax myospalax (Mammalia, Rodentia), cinefluorographical, anatomical, and biomechanical analyses of burrowing // Zoologische Jahrbücher. Abteilung für Anatomie und Ontogenie der Thiere. Bd.123. Hf.4. P.363-401.

Gambaryan P.P. \& Kielan-Jaworowska Z. 1997. Sprawling versus parasagittal stance in multituberculate mammals // Acta Palaeontologica Polonica. Vol.42. No.1. P.13-44.

Gasc J.-P., Jouffroy F.K., Renous S. \& von Blottnitz F. 1986. Morphofunctional study of the digging system of the Namib Desert golden mole (Eremitalpa granti namibensis): cinefluorographical and anatomical analysis // Journal of Zoology, London. Series A. Vol.208. No.1. P.9-35.

Gordon A.M., Huxley A.F. \& Julian F.J. 1966. The variation in isometric tension with sarcomere length in vertebrate muscle fibers // Journal of Physiology Vol.184. No.2. P.170-181.

Hildebrand M. 1985. Digging of quadrupeds // Hildebrand M., Bramble D.M., Liem K.F. \& Wake D. (eds.). Functional Vertebrate Morphology. Cambridge (Mass.) \& London: Harvard University Press. P.89-109.

Hill A.V. 1948. The pressure developed in a muscle during 
contraction // Journal of Physiology, London. Vol.107. No.5. P.518-526.

Hisaw F.L. 1923. Observations on the burrowing habits of mole (Scalopus aquaticus mahrinoides) // Journal of Mammalogy. Vol.4. No.2. P.79-88.

Howell A.B. 1936. The phylogenetic arrangement of the muscular system // Anatomical Record. Vol.66. No.3. P.295-316.

Jenkins F.A., Jr. 1970. Limb movements in a monotreme (Tachyglossus aculeatus): a cineradiographic analysis // Science. Vol.168. No.3938. P.1473-1475.

Laville E. 1988. Etude morphofonctionnelle et evolutive de l'adaptation au fouissage chez Arvicola terrestris Scherman (Mammalia, Rodentia) // Thèse de l'Université Paris. No.7. $124 \mathrm{p}$.

Leche W. 1880. Zur Anatomie der Beckenregion bei Insectivora // Vorlaufige Mittheilung. Morphologische Jahrbücher. Bd.6. Hf.5. S.597-602.

Kielan-Jaworowska Z. \& Gambaryan P.P. 1994. Postcranial anatomy and habits of Asian multituberculate mammals // Fossils and Strata. No.36. 92 p.
Nikolskii V.S. 1978. [General principles of biomechanics of the pectoral girdle and forelimb in Talpa europaea] // Zoologicheskii Zhurnal. T.57. No.7. P.750-758 [in Russian].

Pridmore P.A. 1985. Terrestrial locomotion in Monotremes (Mammalia: Monotremata) // Journal of Zoology London, Series A. Vol.205. Pt.1. P.53-73.

Reed C.A. 1951. Locomotion and appendicular anatomy in three soricoid insectivores // American Midland Naturalist. Vol.45. No.3. P.513-671.

Skoczen S. 1958. Tunnel digging by the mole (Talpa europaea Linne) // Acta Theriologica. Vol.2. No.11. P.235249.

Schmidt-Nielsen K. 1983. Animal Physiology. Adaptation and Environment. Cambridge: Cambridge University Press (Third Edition). 619 p.

Todorowa Z. 1927. Die Enstehungen der Grabanpassungen bei Talpa europaea // Gegenbaurs Morphologische Jahrbücher. Bd.57. Hf.3. S.381-409.

Yalden D.W. 1966. The anatomy of mole locomotion // Journal of Zoology, London. Vol.149. No.1. P.55-64. 